\title{
Educando a Marte. Rentabilidad de la innovación docente militar y versatilidad profesional ${ }^{1}$
}

\author{
$\mathrm{M}^{\mathrm{a}}$ Dolores Herrero Fernández-Quesada ${ }^{2}$
}

Recibido: 4 de junio de 2016 / Aceptado: 22 de julio de 2016

Resumen. Este trabajo se centra en uno de los éxitos del reformismo militar, el nuevo modelo de enseñanza militar y científico-técnica de los Cuerpos Facultativos. La formación del oficial del XVIII será el punto de partida de un intento de aproximación a la rentabilidad de la nueva política educativa y de los colegios militares de ingenieros y artillería, éste último paradigma de la innovación docente militar. $\mathrm{Y}$ desde el universo académico de esta institución, rastreamos la rentabilidad de la educación de Marte y entre sus réditos más notables, se analiza la versatilidad profesional de oficiales que se desenvolvieron en territorios como el espionaje industrial por Europa, trabajando conjuntamente artilleros y el ingeniero Betancourt; o que transitaron de la ciencia a la nueva economía política con naturalidad, como el capitán Vicente Alcalá Galiano.

Palabras clave: reformismo militar; cuerpos facultativos; innovación educativa; ciencia; espionaje; Morla; Betancourt; versatilidad profesional; Alcalá Galiano.

\section{[en] Educating Mars. Educational Innovation Profitability and Professional Versatility}

\begin{abstract}
This paper is focused on one of the successes on military reformism, the new model of military, scientific and technical education of the Facultative Armies. The education of the military officer in the XVIII century will be the starting point in an attempt to approach to the profitability of the new education policy and military schools of engineers and artillery, the latter paradigm of military educational innovation. And from the academic world of this institution, we track the profitability of Mars' education and among its most notable returns, professional versatility of officers who unwrapped in areas such as industrial espionage in Europe is analyzed, working together artillerymen and engineer Betancourt ; or who naturally transited from science to the new political economy, as Captain Vicente Alcalá Galiano did.
\end{abstract}

Keywords: Military Reformism; Facultative Armies; Educational Innovation; Science; Espionaje; Morla; Betancourt; Professional Versatility; Alcalá Galiano.

Sumario. 1. Introducción. Dos interrogantes y alguna excepcionalidad en el cumplimiento de la normativa. 2. Y Marte encontró a Minerva en el nuevo modelo docente de los cuerpos facultativos. 2.1. El debate teórico-práctico. Las crisis en el Colegio Artillero. Calibrando contenidos. 3. Los artilleros o la rentable educación de Marte. 3.1. Versatilidad profesional. Artilleros y el ingeniero Betancourt espian-

\footnotetext{
$1 \quad$ Este artículo se inscribe en el marco del proyecto La voz de las mujeres en la esfera pública (siglos XVII-XX). Entidad financiadora: Ministerio de Economía y Competitividad (HAR2014-53699-R). IP: Rosa Ma Capel Martínez.

2 Universidad Complutense de Madrid (España) mariadhe@ucm.es
} 
do por Europa. 3.2. Versatilidad profesional de los artilleros. De las ciencias a las nuevas ciencias de la Economía Política.

Cómo citar: Herrero Fernández-Quesada, M. ${ }^{\mathrm{a}}$ D. (2016) Educando a Marte. Rentabilidad de la innovación docente militar y versatilidad profesional, en Cuadernos de Historia Moderna 41.2, 391-424.

\section{Introducción. Dos interrogantes y alguna excepcionalidad en el cumplimiento de la normativa}

En el marco de la política militar borbónica de la segunda mitad del siglo XVIII, este trabajo se centra en uno de los éxitos del reformismo focalizados en el nuevo modelo de enseñanza militar para los oficiales de los Cuerpos Facultativos. Partiendo del cuestionamiento del cumplimiento de la normativa ordenancista sobre las condiciones de procedencia social para el ingreso en el ejército o para contraer matrimonio con oficial y sus excepcionalidades, nos interrogamos también sobre la aceptación del nuevo modelo militar, reparando especialmente en el debate sobre la formación de los oficiales, recurrente a lo largo de toda la centuria. La educación del oficial del XVIII será el punto de partida de un intento de aproximación a la rentabilidad de la nueva política educativa militar diseñada para la formación de los oficiales y, más concretamente, la de los colegios militares de ingenieros y artillería, reparando en uno de los paradigmas de la innovación docente militar, el colegio de Segovia. En el universo académico de esta institución, rastreamos la rentabilidad de la educación de Marte y entre sus réditos más notables, se analiza la versatilidad profesional de los oficiales que se desenvolvieron en territorios como el espionaje industrial trabajando conjuntamente artilleros y el ingeniero Betancourt, o que transitaron de la ciencia a la nueva economía política con naturalidad como el capitán Vicente Alcalá Galiano

Con la llegada del primer Borbón y al tiempo que se combate en la Guerra de Sucesión se inicia el proceso de construcción del nuevo modelo militar sobre la base de creación de los ejércitos permanentes ${ }^{3}$, que se fue volcando en ordenanzas y reglamentos sucesivos desde la publicación de las Ordenanzas de Flandes (1702) hasta la edición de las Ordenanzas de Carlos III en $1768^{5}$ con las que se cerró la nueva constitución militar española.

Los Cuerpos Facultativos, ingenieros y artillería, en el marco orgánico de los ejércitos permanentes borbónicos, ya institucionalizados y definidas sus nuevas es-

Rodríguez Hernández, A. J.: "El ejército que heredó Felipe V: su número y su composición humana", en Bernardo Ares, J. M. de (coord.): La sucesión de la Monarquía Hispánica, 1665-1725, Córdoba, Universidad de Córdoba, 2009, pp. 265-301; AndúJar Castillo, F.: "El ejército de Felipe V: Estrategias y problemas de una reforma”, en Serrano Martín, E. (coord.): Felipe Vy su tiempo. Congreso Internacional, Zaragoza, Institución Fernando el Católico, 2004, pp. 661-682; Herrero Fernández-Quesada, M. a D.: "El nuevo modelo de ejército en el contexto de la Guerra de Sucesión Española", en En nombre de la paz. La Guerra de Sucesión Española y los Tratados de Madrid, Utrecht, Rastatt y Baden. 1713-1715, Madrid, Fundación Carlos de Amberes-SECC, 2013, cat. exp., pp. 91-106.

4 Archivo General Militar de Segovia (AGMS), sección 2a , división 10ª leg. 10. Ejemplar impreso.

5 Ordenanzas de S.M. para el Régimen, disciplina, subordinación y servicios de sus Exercitos, Madrid, Oficina de Antonio Marín, 1768, 2 vols. Véase también la recopilación de textos realizada por PortuguÉs, J. A.: Colección de Ordenanzas militares, sus innovaciones y aditamentos, dispuestos en diez tomos, con separación de clases, Madrid, Imprenta de Antonio Marín, 1764; y sobre ella Domínguez NAFríA, J. C.: "Recopilación y codificación del derecho militar en el siglo XVIII: la Colección General de Ordenanzas Militares de José Antonio Portugués", en Martínez Peñas, L., Fernández Rodríguez, M. (coords.): El Ejército y la Armada en el Noroeste de América: Nootka y su tiempo, Madrid, Universidad Rey Juan Carlos, 2011, pp. 211-250. 
tructuras militares y docentes se enfocaron al progreso tecnológico y militar, y a conseguir la mayor utilidad pública de sus luces. Por su concepción, dimensiones y naturaleza, ambos Cuerpos son hijos de la política ilustrada y de la nueva planta militar, y su construcción orgánica y trayectoria a lo largo del XVIII así lo pone de manifiesto. ${ }^{6}$

Sin salirnos del universo de estas dos armas sabias, como punto de partida reflexionamos sobre el éxito del reformismo borbónico en el ámbito de la innovación docente militar. $^{7}$ En ese espacio educativo se produjo el encuentro entre Marte y Minerva, en un siglo en el que se impuso la fundamentación científico-técnica del arte militar. El cambio del modelo docente para la formación de los nuevos oficiales fue decisivo para la forja del alto perfil característico del militar ilustrado, especialmente en los Cuerpos Facultativos. El éxito del reformismo borbónico militar lo encontramos sin duda en la innovación educativa La búsqueda de la excelencia en las cátedras de los colegios militares dotó a los futuros oficiales de una formación de élite y de unas capacidades que derivaron en la versatilidad profesional de que hicieron gala y sobre la que reflexionaremos con casos ilustrativos.

En un volumen dedicado al ejército borbónico, del reformismo al mito, relacionado con el planteamiento anterior de este estudio, y a modo de introducción nos hemos planteado dos interrogantes y constatamos alguna excepcionalidad en procedimientos cerrados del ordenancismo militar del XVIII.

En cuanto a los interrogantes se podrían formular así: primero, ¿Hubo implementación real y seguimiento de las ordenanzas y reglamentos? Y en segundo lugar, ¿Hubo aceptación unánime y sin fisuras del nuevo modelo militar por parte de los integrantes de los Reales Ejércitos Borbónicos, de los nuevos procedimientos y las nuevas coordenadas en las que se movía la carrera militar y su praxis?

En el marco del reformismo militar del XVIII, acumular años de investigación sobre la documentación militar permite topar con claroscuros del modelo militar borbónico, y con discretas conculcaciones de las Ordenanzas, más o menos frecuentes y de diferente calibre y trascendencia institucional. En esta aportación solo me permito recordar alguna de menor calado y relacionada con el tema de desarrollo, pero que puede servir para aprehender las aristas de un aspecto que ha sido seña de identidad de los ejércitos borbónicos: la nueva normativa que determinaba las formas de ingreso en la oficialidad y su procedencia social en la Ilustración.

Desde Felipe V se prestó atención preferente al renovado perfil del militar, de ahí la importancia de dos aspectos que había que regular por medio de ordenanzas y reglamentos. En primer lugar la forma de acceso/ingreso a la oficialidad; y en segundo su instrucción/formación con planteamientos innovadores, que trataremos más adelante. En cuanto al primero, cabe recordar que para transformar la imagen devaluada de la milicia en el siglo anterior y adaptar el perfil de los oficiales al nuevo modelo militar, se reguló ex novo el acceso a los ejércitos, reservándose ser oficial como

Para los ingenieros militares, CAPel, H., SÁnchez, J. E., Moncada, O.: De Palas a Minerva. La formación cientifica y la estructura institucional de los ingenieros en el siglo XVIII, Barcelona, Serbal, 1988; GALLAND Seguela, M.: "Los ingenieros militares españoles en el siglo XVIII", en CÁMARA, A.: (coord.) Los ingenieros militares de la monarquía hispánica en los siglos XVII y XVIII, Madrid, Ministerio de Defensa, 2005, pp. 205229.

7 Véase un estudio reciente Herrero Fernández-Quesada, M. a D.: "La innovación militar en la España del XVIII. Felice Gazzola, Conde de Gazola y el Real Colegio de Artillería. Segovia (1760-1780)", Revista Storica Italiana, 127-1 (2015), pp. 211-247. 
un privilegio otorgado a los hijos de la nobleza en sus diferentes grados o, cuando menos, a quienes pudieran acreditar calidad o ser familia de militares en ejercicio a partir de un determinado grado, habitualmente teniente coronel. Para Andújar este fue un ejercicio de reformulación de la relación de la nobleza con el ejército del que en la centuria anterior se habían apartado. ${ }^{8}$ De ahí que, entre los requisitos para aspirar a plaza de cadete en el ejército, se impusiera la tramitación de memoriales acreditativos de la buena cuna. ${ }^{9}$ La presentación de expedientes de pruebas de nobleza o limpieza de sangre era una condición teóricamente indispensable que extendió la idea genérica de que todos los oficiales eran nobles sin más, como uno de los elementos claves de su nueva imagen. En las últimas décadas la historiografía ha matizado y mucho este aserto.

Por nuestra parte, la investigación en un importante número de expedientes personales y Hojas de Servicio de oficiales del XVIII nos lleva a la localización de informaciones y datos dispersos que facilitan conclusiones abiertas a matices, que queremos traer aquí; y a colegir que efectivamente hubo oficiales nobles y así constaba en las Hojas de Servicio, en el apartado relativo a la "calidad", donde figuraba como noble. Pero la realidad es que en sucesivos trabajos prosopográficos, mayoritariamente nos hemos enfrentado a Hojas de Servicio en las que en "calidad" simplemente figuraba que "la tiene"; o aparece como "notoria", sin informaciones añadidas. Sin duda, entre los oficiales del XVIII también figuran nobles titulados. De hecho, también los primogénitos de las grandes casas acudieron a los nuevos colegios militares a formarse por su excelencia docente, lo que en breve se manifestó como inconveniente para la política educativa militar pues causaban baja al finalizar sus años de academia para ir a atender sus casas perdiéndose oficiales, procediéndose con prontitud a reglar su exclusión en nuevas adendas a las instrucciones de acceso en el caso concreto del Colegio de artillería. ${ }^{10}$

Sin embargo parece claro que dentro del estamento y en sus lindes eran otros los que estaban interesados en el ofrecimiento de la Monarquía de pasar a formar parte de sus cuadros de mando profesionalmente; y que especialmente en la segunda mitad del siglo, se aprecia que también eran otros grupos sociales emergentes los que estaban interesados en la carrera de las armas, profesión que por cierto les proporcionará un modus vivendi, dedicándose a la milicia de por vida. ${ }^{11}$ Luego en la prospección

\footnotetext{
ANDÚJAR Castillo, F.: "Milicia y nobleza. Reformulación de una relación a partir del caso granadino (s.XVII y XVIII)", Jiménez Estrella, A., Andújar CAstillo, F. (eds.): Los nervios de la guerra. Estudios sociales sobre el ejército de la Monarquía Hispánica (ss. XVI-XVIII). Nuevas perspectivas, Granada, Comares, 2007, pp. 251-276; Thompson, I. A.: "Consideraciones sobre el papel de la nobleza como recurso militar en la España Moderna", en Ibidem, pp. 15-36.

9 Pérez Frías, P. L.: "Linaje y élite militar: las pruebas de limpieza de sangre en el Archivo General Militar de Segovia como fuentes documentales", en Soria Mesa, E., Bravo Caro, J. J., Delgado Barrado, J. M. (eds.): Las élites en la época moderna: la monarquía española, Córdoba, Universidad de Córdoba, 2009, vol. IV, pp. 371-384.

10 En 1764 se inició la actividad docente en este centro y en 1776 su Director comunicaba por carta al Consejo Escolar que el rey había decidido que "no se reciban en el Real Colegio Militar de Segovia por alumnos los primogénitos de las familias". Actas del Colegio Militar de Caballeros Cadetes del real Cuerpo de Artillería 1765-1787, manuscrito en dos volúmenes encuadernados en pergamino, Biblioteca de la Academia de Artillería de Segovia (BAAS).

11 AndúJar Castillo, F.: "El ejército borbónico en el último tercio del siglo XVIII: permeabilidad social en una institución nobiliaria”, Chronica Nova, 40 (2014), pp. 131-154; Imízcoz BeunzA, J. M.: "Militares ilustrados. Parentesco, amistad y afinidades políticas en la formación de las élites estatales en el siglo XVIII", en GARCíA Hurtado, M. R. (ed.): Soldados de la Ilustración. El Ejército español en el siglo XVIII", Coruña, Universidad de La Coruña, 2012, pp. 165-214; Imízcoz BeunzA, J. M, ChAPARro, A. (eds.): Educación, redes y producción de élites en el siglo XVIII, Madrid, Sílex, 2013.
} 
en torno a la procedencia social de los oficiales de XVIII se constata la diversidad derivada de la permeabilidad social y emergen los matices que marcan desigualdades notables en la calidad.

De igual forma, en la detección de las presuntas disfunciones en el cumplimiento de la normativa para el ingreso en los ejércitos del XVIII, en segundo lugar traemos aquí para la reflexión un aspecto íntimamente relacionado con el anterior. Lo dicho con respecto a la procedencia nobiliaria de los oficiales, podría afirmarse igualmente sobre sus esposas, singularmente a raíz de la creación por Carlos III del Monte Pio Militar en 1764 para cubrir los imponderables de la viudez o la orfandad. ${ }^{12}$ Estas señoras desde su casamiento pasaban a ser aforadas, a acogerse al fuero militar ${ }^{13}$; y desde la puesta en marcha del Montepío para contraer matrimonio con militar, se regló un procedimiento en el que era indispensable presentar también documentación acreditativa de los orígenes sociales y familiares de las aspirantes a esposas, cuando menos de dos generaciones anteriores. ${ }^{14}$ Los expedientes matrimoniales de oficiales y las testamentarías de sus mujeres ${ }^{15}$, también aforadas, constituyen un excepcional yacimiento documental ${ }^{16}$ que en un futuro podría proporcionar un interesante mapa matrimonial de la oficialidad en el XVIII, que está por hacer, -en la línea de trabajo abierta para los ingenieros militares por Galland ${ }^{17}-$, una cartografía matrimonial de la oficialidad del XVIII donde figuran señoras de la nobleza y también de la Grandeza, pero proporcionalmente las menos. ${ }^{18}$ Por nuestra parte y a partir de una cata realizada sobre expedientes matrimoniales y testamentarías de señoras aforadas casadas con militares de la segunda mitad del XVIII, hemos comprobado que la mayoría de las aspirantes a esposas de oficial demostraban en sus expedientes su calidad y acreditaban limpieza. Esto se confirma también a la hora de trabajar con los testamentos de estas mujeres aforadas que son documentalmente de gran interés, pero numéricamente escasos si los valoramos dentro del cómputo general de matrimonios que se concertaban en la institución. ${ }^{19}$

12 Reglamento de la fundación y establecimiento del Monte Pío Militar, Madrid, Imprenta Real, 1761.

13 AndúJar Castillo, F.: "El fuero militar en el siglo XVIII. Un estatuto de privilegio", Chronica Nova, 23 (1996) pp. 11-31; García de la Rasilla, M. C.: "El Montepío militar. La asistencia social en el ejército en la segunda mitad del siglo XVIII", Revista de Historia Militar, 63 (1987), pp. 123-160.

14 Ocerin y García de Llamera, E.: Índice de los Expedientes Matrimoniales de Militares y Marinos que se conservan en el Archivo General Militar (1761-1865), Madrid, CSIC, Instituto Jerónimo Zurita, 1959, 2 vols. Esta obra nacía con vocación de continuidad en tomos de publicación posterior que no llegaron a editarse, con una previsión a priori de hacer entre cuarenta y cincuenta mil asientos o fichas de cada expediente matrimonial. En el primer tomo se registraron 5375 asientos ordenados alfabéticamente por los apellidos de las señoras aspirantes a casarse. La serie no está catalogada completa y aunque en ambos tomos no aparezca un determinado expediente matrimonial eso no quiere decir que no se encuentre entre los anaqueles del AGMS.

15 Herrero Fernández-Quesada, M. a D.: “¿Una aguja en un pajar...? En torno a un caso de divorcio en los archivos militares", en Hernández SANDOICA, E. (coord.): Espacio público y espacio privado. Miradas desde el sexo y el género, Madrid, Abadá Editores, 2016, pp. 319-356.

16 En los archivos militares y en la documentación que conservan apenas hay rastro de las mujeres, al igual que en la historia militar de España, salvo excepciones. En este sentido véase Herrero FernándeZ-QueSADA, M. ${ }^{a}$ D.: "Necesidad que no virtud. La Compañía de Mujeres de Santa Bárbara en los sitios de Gerona", en CAPEL MarTínEz, R. M. (coord.): Presencia y visibilidad de las mujeres: recuperando historia, Madrid, Abada, 2013, pp. 157-220.

17 Galland Seguela, M.: "Las condiciones materiales de la vida privada de los ingenieros militares en España durante el siglo XVIII", en Scripta Nova. Revista electrónica de Geografia y Ciencias Sociales, 8 (2004), pp.157-180.

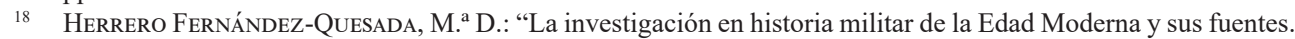
El Archivo General Militar de Segovia, Decano de los archivos militares españoles", Cuadernos de Historia Moderna, 38 (2012), pp. 165-214.

19 Borrero y de Roldán, F. L.: Índice genealógico de los oficiales del Real Colegio de Artillería y matrimonios de los mismos (1765-1808), Madrid, Real Consejo de Órdenes Militares-IHCM, 2005, 2 volúmenes. 
Por tanto, también la desigualdad en los orígenes de las aspirantes a contraer matrimonio con militares es un hecho comprobable desde la institucionalización del Monte Pio Militar, constatado en la documentación de la propia Secretaría del Despacho que tenía todas las competencias en esta materia y donde llegaban todos los Expedientes Matrimoniales que se cursaban por parte de los oficiales y las candidatas a esposa para obtener la correspondiente licencia de casamiento. En la Secretaria se revisaba escrupulosamente toda la documentación, contrastándola de tal manera que encontramos cómo ciertamente se devolvían algunos y se solicitaba con frecuencia que se aportaran nuevos documentos más explícitos, que no ofrecieran dudas sobre el origen social y familiar de la candidata. ${ }^{20}$

Llegados a este punto, también se podría cuestionar el cumplimiento al cien por cien de la legislación matrimonial del Monte Pio, transmitida aparentemente sin fisuras con respecto a los desposorios de los militares del XVIII, de importancia capital desde el reinado de Carlos III. La elección de esposa condicionaba la arquitectura familiar de los oficiales dieciochescos, su origen, su trayectoria familiar intachable debían quedar acreditadas y estaban estrechamente relacionados con el nivel de formación de la mujer necesario a aquellas alturas del siglo ilustrado, que debía garantizar la acertada educación de los hijos, mayoritariamente en sus manos. El modelo familiar tradicional era el que apuntalaba la vida - muchas veces itinerante-del militar. La movilidad inherente a su profesión hacía de la esposa el eje -invisible y silente- de la vida familiar ${ }^{21}$, y los militares - que venían de entornos familiares tradicionales- apuntalaban sus propias familias sobre esas coordenadas. O no siempre. El rastro de una casuística excepcional no es fácil de seguir en la documentación institucional, aunque finalmente la investigación en la personal y profesional de los militares también desvela pistas discretas sobre casos fuera de los márgenes. Sin duda, una mayoría de militares y marinos se sujetaba a los procedimientos reglados para contraer matrimonio, pero inesperadamente detectamos que hay resistencias puntuales a presentar la documentación ante la Secretaria del Despacho como era preceptivo para conseguir la licencia matrimonial, trampeando, echándole imaginación y casándose sin permiso al margen de la normativa. Solo por citar un caso, traemos aquí el del aragonés Joaquín de la Pezuela ${ }^{22}$ quien sin trámites ni expediente de por medio, sin autorizaciones familiares ni institucionales, obviando jerarquías, reglamentos, procedimientos y montepíos, se llevó literalmente a su amada para convertirla en su mujer al salir de España para asumir su destino en América. ${ }^{23}$ Este acto de insumisión que, sin duda, trascendió, no tuvo consecuencias para Pezuela por estar destinado en Ultramar y posiblemente por su excelente trayectoria profesional en América. El escándalo y la interpretación de su acción por algunos como secuestro no impidió al oficial finalmente llegar a ser Virrey del Perú ${ }^{24}$, y nombrado primer Marqués de Viluma.

20 Este caso no es infrecuente y se dio en la probanza de Manuela Vázquez Vázquez aspirante a esposa del oficial Vicente María de Maturana, quien para el Fiscal Militar "no justificaba debidamente su nobleza", AGMS, sección 1 ${ }^{\mathrm{a}}$, leg. M-2353. Expediente Matrimonial de Vicente M. ${ }^{\mathrm{a}}$ de MATURANA ALTAMIR.

21 Herrero FernándeZ-Quesada, op. cit. (nota 15).

22 AGMS, Célebres, caja 133, exp. 1. Expediente Personal de Joaquín de la Pezuela Sanchez-Capay, Marqués de Viluma.

23 Herrero Fernández-Quesada, M. a D.: "Consideraciones en torno a la figura de Joaquín de la Pezuela: el impulso de la artillería en el Virreinato del Perú a principios del siglo XIX, y su etapa como Virrey", en Actas del II Congreso Internacional de Historia Militar, Zaragoza, Universidad de Zaragoza-Academia General Millitar, 1989, pp. 366-373.

24 Véase la biografía de su hijo, Juan de la Pezuela, Conde de Cheste. Rozalejo, MarquÉs DE: Cheste o todo un siglo (1809-1906), Madrid, Espasa Calpe, 1935. 
Además, en este estudio, señalaremos únicamente dos casos indicativos de la laxitud ocasional en el cumplimiento de la normativa, entreverada en la documentación. En cuanto al primero de ellos cabe recordar que junto al origen social, la procedencia familiar, pertenecer a una familia estructurada parecía un requisito indispensable que también se acreditaba y en la Secretaría del Despacho se verificaba aplicando los filtros que fueran necesarios. Sin embargo, algunos aspirantes a futuros oficiales lograban ingresar en el ejército en medio de situaciones familiares complicadas que, teóricamente, dificultarían su candidatura para la obtención de plaza. En este sentido, es ilustrativo el caso del aspirante a Caballero Cadete Luis García de la Huerta ${ }^{25}$, después reputado oficial, traductor y autor científico quien en 1777 ingresó en el Real Colegio de Artillería habiendo presentado un memorial documental que pasó todos los filtros, con documentación oficial y políticamente correcta. Este alumno, hijo de doña Gertrudis Carrera Larrea y del conocido escritor Vicente García de la Huerta ${ }^{26}$, funcionario en la Corte al ostentar un cargo en la Biblioteca Real, académico y archivero de la Casa de Alba, ingresaba en aquella academia mientras su padre -antiarandista ya desterrado a Orán temporalmente, por motivos políticospresentaba ante los tribunales una denuncia de adulterio contra su mujer. ${ }^{27} \mathrm{Sin}$ embargo, este paisaje familiar en proceso de desestructuración pública, es obviado en la documentación y en su posterior admisión, aunque sobradamente conocido en el colegio artillero, en la Secretaría del Despacho y en la Corte.

La más que posible explicación a esto, la encontramos en una variable no explicitada en la normativa de ingreso en los ejércitos pero ciertamente determinante en los procesos de admisión de los aspirantes a los colegios militares y al ejército, el capital relacional, definido en su momento por Imizcoz. ${ }^{28}$ Las familias recurrían a los contactos, a sus agendas, a ese capital relacional que tanto dinamismo proporcionó a las nuevas élites sociales en la segunda mitad del XVIII. A los expedientes de ingreso, les acompañaban subliminalmente y sin dejar apenas rastro las gestiones directas, las cartas de recomendación y avales de familiares o amigos bien posicionados. En este sentido cabe recordar el trabajo de Imízcoz sobre Luis Gonzaga y su ingreso en el Real Colegio de Segovia, en una convocatoria a la que acudieron 150 aspirantes y solo ingresaron 11, entre ellos el Cadete Gonzaga gracias a las gestiones que se hicieron en el entorno del Conde de Lacy, Director del centro. ${ }^{29}$

Para finalizar en el marco de la familia militar y sus disfunciones, incorporamos a las excepcionalidades el caso del oficial de infantería Don Luis Moreno Monroy que ingresó en los ejércitos más bien justo en lo que respecta a sus requisitos relativos al origen familiar y su calidad, para ilustrar la ruptura familiar. Pero una vez

25 AGMS, Sección 1a ${ }^{\text {a }}$ leg. G-1477. Expediente Personal de Luis García de la Huerta.

26 Sobre la controvertida figura de su padre, Vicente García de la Huerta, véase BusQuETs, L.: "Sobre García de la Huerta, teórico y traductor”, Cuadernos dieciochistas, 3 (2002), pp. 149-175; GARCíA-HuRTADO, M. R.: El arma de la palabra. Los militares españoles y la cultura escrita en el siglo XVIII (1700-1808), Coruña, Universidad de la Coruña, 2002, pp. 170-180.

27 García de la Huerta, L.: Discurso físico-anatómico sobre las plantas. Segovia, 1790. Edición Facsímil. Estudio preliminar y notas de J. M. Valles Garrido y J. L. García Hourcade, Segovia, BCA, 1990; Gomis Blanco, A., Pelayo López, F., Gago Bohórquez, R.: "La fisiología y la química vegetal en España. Algunas consideraciones sobre el Discurso de Luis García de la Huerta”, en Hormigón, M. (ed.): Actas del II Congreso de la Sociedad Española de Historia de las Ciencias, Zaragoza, SEHC, 1984, vol. 3, pp.79-92.

28 Imízcoz BeunzA, J. M.: "El capital relacional. Relaciones privilegiadas y redes de influencia en el estado español del siglo XVIII", en Imízcoz Beunza, J. M., Oliveri KorTA, O. (coords.): Economía doméstica y redes sociales en el Antiguo Régimen, Madrid, Sílex, 2010, pp. 227-281.

29 Ibidem, p. 231. 
dentro, todo parece indicar que quiso paliar sus carencias sociales y, sin duda, económicas. Se casó con doña Francisca Barba Osorio ${ }^{30}$, Marquesa de Castrofuerte, quien además de ser la titular de un mayorazgo en la provincia de Burgos, contaba con una economía más que saneada que venía a inyectar liquidez en la vida del oficial quien dispuso sin medida de ella, viviendo y malgastando el patrimonio de su mujer. Las posibilidades de promoción social que le brindó su ingreso en el ejército fueron muy aprovechadas por este oficial. Y lo que parecía imposible, sucedió, encontramos en documentación de la aforada Marquesa, en su legajo testamentario más concretamente que ella solicitó literalmente el divorcio (sin que existiera legalmente) de su marido ante la jurisdicción civil ${ }^{31}$, suscitándose un pleito no solo de cónyuges sino de jurisdicciones puesto que el oficial cruzó en este proceso la jurisdicción militar haciendo valer su aforamiento. ${ }^{32}$

La imagen compacta de la familia militar en el XVIII es ciertamente, y de forma mayoritaria, real, pero también hay espacio para el trecho que va del dicho y al hecho, hay un espacio para las excepcionalidades que a la luz de la documentación no son pocas y eso sin entrar aquí en la amplia casuística de los destinados a América, algunos de los cuales dejaron familia en España. Sin embargo, y a pesar de los versos sueltos si algo queda claro es que la institución militar y su jurisdicción velaban por las apariencias y por la protección del modelo familiar indicando a la Marquesa de Castrofuerte que hasta que hubiera un fallo judicial al respecto, debía convivir obligatoriamente con su marido para guardar las formas convenientes a la institución. ${ }^{33}$ Curiosamente y, en este caso, hubo desobediencia por parte de la mujer que se mantuvo en la separación de hecho del oficial, y finalmente testó y murió sin fallo judicial a su demanda de divorcio, como era previsible por otra parte. El tiempo como factor de dilación en este tipo de procesos era moneda de curso legal, y la solución a medio o largo plazo. Por tanto, entre los oficiales del XVIII hubo incumplimientos de la normativa matrimonial, deconstrucción del modelo familiar e insumisión clara, en este último caso, a la hora de acatar las órdenes de la jurisdicción militar en el ámbito familiar, acompañado de una firme voluntad de deshacer el vínculo y la familia formada.

En el XVIII tan importante era serlo como parecerlo, y más aún en una institución como la militar. La imagen de la familia militar se regulaba por medio de reglamentos y ordenanzas y se protegía desde la institución desde donde se proyectaba socialmente, compacta y modélica. Enlazando con esto y como colofón a esta aportación microhistórica para la reflexión, en la visibilidad de una casuística variada y excepcional que tiene que ver con el origen social y con la estructura familiar de los militares del XVIII, la documentación trabajada permite comprobar cómo a los ofi-

30 AGMS, sección 9 ${ }^{\text {a }}$, Expediente 4458. Testamentaría de Doña Francisca Barba Osorio, Marquesa de Castrofuerte). 18 de octubre de 1775

31 Memorial de la Marquesa de Castrofuerte fechado el 15 de octubre de 1764, solicitando instruir pleito criminal para la consecución del divorcio, AGMS, sección 9 ${ }^{a}$, expediente 4458. Testamentaría de Doña Francisca Barba Osorio, Marquesa de Castrofuerte.

32 Herrero FernándeZ-Quesada, op. cit. (nota 15).

33 Véase Macías Domínguez, A. M.: "Vidas separadas según las posibilidades de Trento: las demandas de nulidades matrimoniales en el siglo XVIII", en CANDAU CHACón, M. L. (ed.): Las mujeres y el honor en la Europa Moderna, Huelva, Universidad de Huelva, 2014, pp. 271-300; Ruíz SASTRE, M., Macías Domínguez, A. M.: "La pareja deshecha: pleitos matrimoniales en el tribunal arzobispal de Sevilla durante el Antiguo Régimen”, Erebea. Revista de Humanidades y Ciencias Sociales, II (2012), pp. 273-279; y López-CoRdón, M. V.: "Familia, sexo y género en la España Moderna", Studia histórica. Historia Moderna, 18 (1998), pp. 105-134. 
ciales les causaba rubor no contar con una familia que se ajustase a las coordenadas de los reglado, y recurrían también al disimulo y al engaño en un intento de guardar la apariencia socialmente. Y en esa tesitura encontramos a José Meneses y Montemayor ${ }^{34}$, antiguo oficial de la Armada, quien después pasó a formar parte del Cuerpo de Artillería en $1808^{35}$, que en 1795 se casó con Doña María de los Rius y Charlán ${ }^{36}$ "señora apreciada por su clase" ${ }^{37}$ con quien tuvo dos hijos. Meneses llegó a falsear su estado civil en la documentación oficial, poniéndose como viudo, avergonzado -según sus propias palabras- de tener una mujer muy gastadora, que dilapidaba el patrimonio, de la que se separó en 1802, arguyendo el bienestar de sus hijos. Al finalizar la Guerra de la Independencia aseguraba sentir "bochorno" a la hora de comentar a sus compañeros que estaba separado. Sin embargo, su mala conciencia por el engaño sostenido en el tiempo que nadie había detectado, le llevó a confesar a sus superiores el fraude que justificaba porque "este rubor ha sido causa que en mis anteriores hojas de servicio cometiese la falta de suponerme el estado de viudo", y mostrándose arrepentido por la falsificación documental notificaba su estado real, para que -aunque separado- figurase en su hoja de Servicios como casado, y así figura en la última de su servicio activo que se cerró en 1820, consiguiendo de sus superiores la corrección de todas las anteriores.

Como un elemento más en torno a la cuestión del mito del reformismo borbónico, volvemos a interrogarnos ¿Implementación real, pragmática y unánime de las ordenanzas y reglamentos? Por investigaciones conocidas, quedó claro que no en los asuntos de gran calado como la promoción en los ascensos o la venalidad ${ }^{38}$, pero como hemos visto hasta aquí- tampoco en cuestiones perfectamente reglamentadas como la rigidez en el cumplimiento de los requisitos de ingreso para los oficiales y en la articulación de los matrimonios de los oficiales y el entorno familiar de procedencia. Asuntos estos de vital importancia en la forja de la nueva y renovada imagen del militar borbónico y en la difusión social de su buena prensa. El reformismo exitoso compacto y sin fisuras, el cumplimiento de la Ordenanzas y las normas inexcusable y a rajatabla, no parece que cubriera el cien por cien del espectro institucional y procedimental.

Por otra parte, en la evocación de las luces y sombras del nuevo modelo militar, en investigaciones realizadas previamente, ha ido emergiendo una duda transversal que se planteaba recurrentemente en la consulta de la documentación y que nos lleva al segundo de los interrogantes planteados en la introducción de este estudio. ¿Hubo aceptación unánime y sin fisuras por parte de los militares que integraban los Reales Ejércitos Borbónicos del nuevo modelo, los nuevos procedimientos y las nuevas coordenadas en las que se movía la carrera militar y su praxis en los ejércitos permanentes? Que hubo una mayoría de nuevo ingreso en la milicia, que empatizó, ciertamente sí. Pero es posible que estemos, sin embargo, ante otro claroscuro del reformismo militar borbónico en construcción durante y después de la Guerra de

34 AGMS, sección $1^{\mathrm{a}}$, división $1^{\mathrm{a}}$, leg. M-2901. Expediente Personal de José Meneses y Montemayor.

35 Hoja de Servicios de este oficial, cerrada en 1820 en la que figura corregido el estado civil, AGMS, sección 1a, división $1^{\mathrm{a}}$, leg. M-2901.

36 Expediente matrimonial integrado en el Expediente Personal de Montemayor. AGMS, sección $1^{\mathrm{a}}$, división $1^{\mathrm{a}}$, leg. M-2901.

37 Memorial dirigido al Director General de Artillería, fechado en Toledo a 28 de enero de 1815 donde hace un relato exhaustivo, AGMS, sección 1ª división 1a leg. M-2901.

38 AndúJar Castillo, F.: El sonido del dinero. Monarquía, ejército y venalidad en la España del siglo XVIII, Madrid, Marcial Pons, 2004. 
Sucesión y sostenido por el diseño posterior del modelo militar ya en tiempo de paz. No podemos olvidar que, además de la selección de una oficialidad escogida, la fidelización de los oficiales por parte de la nueva Monarquía fue uno de los aspectos claves en el proceso de formación de los ejércitos permanentes. ${ }^{39}$

En este sentido, una breve cuestión y algún interrogante derivado del anterior ¿Esa aceptación y empatía con el nuevo modelo militar fue conceptual y/o generacional? ¿O solo generacional como podríamos pensar por lógica en un principio? Los más veteranos tenían una conceptualización de la profesión militar más vinculada a la práctica empírica del arte militar, entonces ¿eran ellos los críticos que lo cuestionaban? ¿Y los que empatizaron con el nuevo modelo, con la nueva orientación de la carrera militar metabolizándolo como propio y trabajando por su progreso y éxito, eran acaso en su mayoría jóvenes de nuevo ingreso en los ejércitos? Esta última tesis sería perfectamente compatible con la generacional: los veteranos defensores de su propio cursus honorum, de la tradición militar española y del empirismo en la praxis de la profesión como fuente de conocimiento; y las nuevas generaciones de oficiales ilustrados, formadas en los nuevos postulados de la ciencia y la técnica militar abiertas al futuro de progreso. Se tiende a pensar que los cambios y las reformas son mal aceptados por los más mayores y que, sin embargo, se reciben con entusiasmo generalizado por los jóvenes, y no siempre es así.

Sin embargo, lo que nos interesa destacar aquí, por el tema central de esta aportación, es que el grueso y el fundamento del debate sobre el modelo militar borbónico y la clave de su aceptación y de la discusión estaba sin duda en un polémico punto, la formación de los cuadros de mando. ${ }^{40}$ En el pasado primaba el aprendizaje empírico para el dominio de la profesión y de las destrezas militares. Como es conocido, en el siglo de la Ilustración heredero de la anterior revolución científica, la nueva dinastía centró sus esfuerzos en la renovación de la formación militar, tanto en las unidades con la figura del Cadete de Regimiento, como -y especialmente- en la Armada y en los Cuerpos Facultativos que contaron con colegios y academias para la formación de la nueva oficialidad, basada -en el caso de estos últimos- en la fundamentación científico-técnica de la ingeniería militar y de la artillería como sistema de armas puntero. $^{41}$

En el siglo XVIII los veteranos militares tuvieron que trabajar y combatir, llegado el caso, con las nuevas generaciones de oficiales, y la convivencia profesional fue origen de cuestionamientos y comparaciones. Pero no siempre de desencuentros y para ilustrarlo conviene en este punto recordar casos como el de José Datoli, napolitano al servicio de la Monarquía en tierras italianas y en la Península después. ${ }^{42}$ Datoli formado en aquel reino donde sirvió en la artillería napolitana, también participó en las campañas de Italia. Sin embargo en sus destinos en la Península cuenta

39 Andúuar Castillo, F.: "La Corte y los militares en el siglo XVIII", Estudis. Revista de Historia Moderna, 27 (2001), pp. 91-122; Glesener, T.: "La hora felipista del siglo XVIII: auge y ocaso de la nación flamenca en el ejército borbónico", Cuadernos de Historia Moderna. Anejo X (2011), pp. 77-101; Glesener, T.: "Tiempos de incertidumbre: las familias flamencas y la emigración militar s España a principios del siglo XVIII", en VILLAR García, M. B. y Pezzi Cristóbal, P. (eds.): Los extranjeros en la España Moderna. Actas del I Coloquio Internacional, Málaga, Gráficas Digarza, 2003, pp. 353-364.

40 AndúJar, F.: "La educación de los militares en la España del siglo XVIII”, Chronica Nova, 19 (1991), pp. $245-276$.

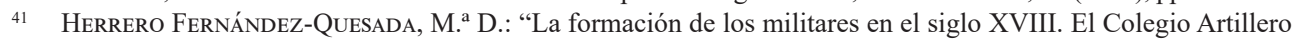
de Segovia o la creación de un modelo", en Imízcoz Beunza, Chaparro, op. cit. (nota 11), pp. 317-336.

42 Expediente Personal de José Dattoli, AGMS, sección 1ª leg. D- 92. Perteneció al grupo de italianos que participaron en las campañas de Italia con Carlos de Nápoles 
con una Hoja de Servicios muy notable, y con una aportación reseñable en la construcción de la nueva política docente militar durante los reinados de Fernando VI y Carlos III. Fue profesor en el Colegio de Cádiz ${ }^{43}$, participó en el ambicioso e innovador proyecto del Conde de Aranda, la Real Sociedad Matemática de Madrid ${ }^{44}$, planteada con criterios orientados a la investigación del arte militar, singularmente de la ingeniería y la artillería. Y precisamente por este bagaje profesional y científico, contribuyó al impulso para la apertura y etapa fundacional del Colegio de Artillería de Segovia, donde se apuntalaba desde las cátedras su vis científico-técnica irrenunciable de los estudios en aquella academia, enunciada y anunciada por el Jefe de Estudios en su lección de apertura, y por la que apostaban todos los profesores siguiendo el innovador ideario docente del Conde de Gazola, su Director. ${ }^{45}$

En suma, y a pesar de su encuadre generacional, encontramos en José Dátoli un perfil de oficial de artillería más científico-técnico que empírico a pesar de no haberse formado en academias y de pertenecer por edad a una época previa a la institucionalización de la enseñanza artillera en la segunda mitad del XVIII. Su trayectoria profesional viene a ratificar la idea de que no todos los veteranos oficiales eran partidarios del pasado empírico de la milicia, sino que más bien al contrario algunos eran defensores de los fundamentos científico-técnicos del arte militar, de la innovación docente y capaces además de construir las bases de la misma, como fue el caso de Datoli.

Sin duda, el debate entre el pasado y el presente de la milicia, estará latente a lo largo de todo el XVIII, especialmente centrado en el nuevo modelo de formación de los oficiales. De hecho, en mi opinión, Cadalso desde una perspectiva amplia del siglo lo recoge en su última obra, El buen militar a la violeta ${ }^{46}$, pasándolo por el filtro de la sátira que tanto dominaba. Así, a finales del siglo, el Capitán a la Violeta como profesor en la obra, se convierte en asesor de imagen de la juventud militar española que tendrá que representar su papel de buen militar, en sociedad tal y como retrata en su escrito dirigido a quien consideraba una autoridad en el tema, Don Joseph Vazquez, catedrático a la Violeta, el máximo rango, y autor de lo que denomina el "Curso de Erudición a la Violeta, con que Vmd sirve al Público", estructurado en siete lecciones que contienen "lo que corresponde a cada cual en la Sociedad". Como punto de partida de su obra, planteada con vocación docente y sobre todo de utilidad práctica al colectivo, decidió "sujetar todos los principios de la Teórica Militar al suave y útil imperio de la moda", lo que ya de por si es significativo.

Con un cierto punto de frivolización aparente de la profesión militar, Cadalso centra su obra en el proceso de forja de la imagen del militar violeto, incluyendo recomendaciones múltiples y variopintas que serán de utilidad al joven oficial para la correcta percepción de su imagen pública en sociedad. Se trataba no solo de ser militar, sino de parecerlo, las apariencias había que cuidarlas con el fin de proyectar una imagen creíble, de "sostener mejor la ilusión" social.

43 Herrero Fernández-Quesada, M. ${ }^{a}$ D.: "Enseñanza, ciencia y técnica. Los primeros Borbones. Colegios y fábricas”, en VALdÉS SÁNCHEZ, A. (coord.): Historia de la artillería de costa en España, Madrid, Ministerio de Defensa, 2014, pp. 135-144.

44 Marzal Martínez, A.: "Un ejemplo de renovación científica en la Ilustración: la Real Sociedad Militar de Matemáticas de Madrid", en Actas del I Congreso de Historia Militar. Zaragoza, AGM-Universidad de Zaragoza, 1986; Herrero Fernández-QuesadA, M. ${ }^{a}$ D.: La enseñanza militar ilustrada. El Real Colegio de Artillería de Segovia, Segovia, BCA, 1990.

45 Herrero FernándeZ-Quesada, op. cit. (nota 7).

46 CAdalso, J.: El buen militar a la violeta. Lección póstuma del autor del tratado de los eruditos, Sevilla, Imp. Mayor de la ciudad, 1790. 
Es posible que aún a finales de la centuria reflejara el sentir de algunos escépticos, al describir el perfil oficial científico-técnico cuando aconsejaba posturas y puestas en escena determinadas a los aspirantes a oficiales en la segunda mitad del siglo para aparentar ser. Al hilo de ello, es particularmente revelador el capítulo de los consejos que debían seguir incluso en su espacio más íntimo, en las habitaciones que ocupaban ocasionalmente como las de una posada sujetas a los ojos de los demás. Cadalso recomendaba al oficial una puesta en escena para aparentar su vis científica, en la que todo debía ajustarse al guión que delimitaba los contornos del buen militar, y que contemplaba incluso cómo debe ser y estar su mesa de trabajo, donde siempre encontraríamos desplegado un mapa geográfico, un "estuche matemático", planos inconclusos y, lo fundamental: "todo amontonado y confuso, como que manifiesta haberse separado de la mesa fatigado del trabajo, y sin ánimo para dexar ordenados los papeles, pues toda esta, aunque comunísma impostura, produce favorables efectos, haciendo creer a los ignorantes mucho ingenio y aplicación..."47

Sin embargo, en el caso de los oficiales de los Cuerpos Facultativos esa excelencia científico-técnica en su formación, no era apariencia, era real, acreditada y reconocida por otros militares de mejor o peor grado. Ninguna figura más lejos del petimetre que los oficiales de artillería e ingenieros, de tal manera que no nos resistimos antes de entrar en ello a reproducir la mordaz expresión que acuñó Cadalso para hacer referencia a la densa educación científica que recibían los artilleros, "erudición morteril" 48 , erudición sí, pero referida a los morteros como piezas de artillería pesada.

\section{Y Marte encontró a Minerva en el nuevo modelo docente de los cuerpos facultativos}

En el marco del debate general sobre la profesión y los dos modelos de instrucción militar, la discusión sobre las reformas en la enseñanza militar tan determinante para la formación del perfil del oficial borbónico, sobre los nuevos pilares de la innovación educativa, fue recurrente a lo largo de la centuria ilustrada, también en el seno de las Armas Sabias que habían incorporado una potente carga científico-técnica a sus estudios.

A lo largo del XVIII, las nuevas coordenadas que marcaron la innovación docente militar fueron objeto de debate intergeneracional entre los profesionales de la milicia. Pero si en el contexto del reformismo militar borbónico hay algún aspecto del que podamos hablar abiertamente de éxitos y que permita focalizar las luces del reformismo militar ese es, sin duda, la innovación educativa que se implementó en la Armada $^{49}$ y en los Cuerpos Facultativos. Los cambios y reformas iniciales dieron

Ibidem, p. XII.

48 Esta expresión se incluye en su obra más conocida sobre los violetos. CADALSO, J.: Los eruditos a la violeta o curso completo de todas las ciencias dividido en siete lecciones para los siete días de la semana, compuesto por José Vazquez, quien lo publica en obsequio de los que pretenden saber mucho, estudiando poco, Madrid, Imp. A. Sancha, 1782, p. 111.

49 Lafuente, A., Mazuecos, A.: Los caballeros del punto fijo. Ciencia, politica y aventura en la expedición hispanofrancesa al virreinato del Perú en el siglo XVIII, Madrid, Serbal, 1987; y LAFuenTe, A., SELlÉs, M.: "El proceso de institucionalización de la Academia de Guardiasmarinas de Cádiz (1717-1748)", en EcheVARRÍA, J., De Mora, M. (coords.): Actas del III Congreso de la Sociedad Española de Historia de las Ciencias, San Sebastián, Editorial Guipuzcoana,1986, vol. II, pp. 153-176. 
lugar a la nueva estructura de la instrucción militar en los ejércitos y la marina borbónicos, a la nueva planta militar y por fin, a la institucionalización de la enseñanza militar en los cuerpos de ingenieros y artillería, que también quedaron ya definitivamente integrados con carácter permanente en las nuevas estructuras militares, con entidad independiente dentro del modelo militar borbónico. ${ }^{50}$ Sin duda, representaron pronto el nuevo y vigoroso tejido profesional de los ejércitos borbónicos.

Estos dos Cuerpos Facultativos, minoritarios desde el punto de vista cuantitativo en las estructuras de los Reales Ejércitos permanentes, pero cualitativamente importantes, fueron organizados a través de Reglamentos de creación y en ambos se fijó como objetivo prioritario e indispensable, la reformulación definitiva de la instrucción de su oficialidad con la apertura de escuelas y colegios.

La formación y organización permanente de ambos cuerpos y de sus modelos de instrucción de oficiales, los colegios, responde a uno de los objetivos prioritarios del nuevo modelo militar, pero la naturaleza y trascendencia del proceso hace que podamos analizarla dentro del proyecto de Estado Borbónico. Y será en ese espacio de la nueva planta militar donde Marte encontrará a Minerva. Para los ingenieros, en un momento en el que en Europa políticos y diplomáticos se ocupaban de la definición precisa de las fronteras en el continente, tan trascendente en la paz y en la guerra como se encargó de demostrar Luis XIV. ${ }^{51}$ Al inicio del siglo XVIII los ingenieros militares tenían la responsabilidad de responder profesionalmente y con solvencia a la defensa del territorio de la Monarquía. ${ }^{52}$ Pero además - siguiendo los nuevos postulados del reformismo- debían asumir todo lo concerniente a la arquitectura militar (adaptada o de nueva traza) que daría seguridad a las fronteras y puntos defensivos polémicos, no solo peninsulares sino también $-\mathrm{y}$ ya con carácter de urgencia- de Ultramar.

Históricamente el arte de fortificar había ganado en complejidad, más aún desde los inicios de la Edad Moderna, y cada vez era más deudor de los avances científicotécnicos, más aún de Vauban en adelante con la asunción unánime por parte de todos los estados de su sistema de fortificación abaluartado, y la guerra de ataque y defensa de plazas. Esta realidad ya se había constatado con Carlos II y una prueba de ello se encuentra en la Academia Militar de Bruselas que pivotó en torno a la figura de Fernández de Medrano ${ }^{53}$, quien creó un centro para instruir a los oficiales con un perfil que les permitiese el ejercicio de su profesión sin carencias en la formación científico-técnica. ${ }^{54}$ Esta institución pionera marcó la hoja de ruta de la enseñanza de los ingenieros a medio y largo plazo, sería uno de esos elementos que apuntan a la continuidad con respecto al modelo militar anterior. ${ }^{55}$ La Academia de Bruselas

50 Herrero Fernández-Quesada, op. cit. (nota 3); Cepeda Gómez, J.: "La historia bélica de la Guerra de Sucesión", en En nombre de la paz..., op. cit. (nota 3), pp. 107-124.

51 BÉLY, L.: "La representación dela frontera en las diplomacias durante la Edad Moderna", Manuscrits, 26 (2008), pp. 35-51.

52 CÁMARA, op. cit. (nota 6).

53 Rodríguez Villa, A.: Noticia biográfica de don Sebastián Fernández de Medrano. Madrid, Tip. M. G. Hernández, 1882; Herrero Fernández-QuesadA, M. a D.: "Breve aproximación a la historia de la enseñanza militar", en Aproximación a la historia militar de España, Madrid, Ministerio de Defensa, 2006, pp. 935-947.

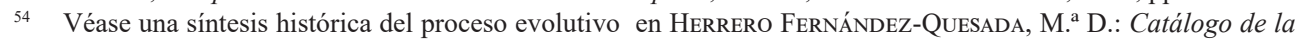
biblioteca del Real Colegio de Artillería de Segovia. II. Fondos artilleros y de fortificación. Estudio Preliminar, Segovia, BCA, 1992.; Herrero Fernández-Quesada, M. a D.: "Ciencia y técnica militar" en Aproximación a la historia militar..., op. cit. (nota 53), pp. 831-858.

55 Rodríguez HernáNDEZ, op. cit. (nota 3), pp. 265-301. 
situó el punto de partida claramente, trazó el camino de los cambios necesarios en la instrucción militar, e inspiró una buena parte de las reformas que con Felipe $\mathrm{V}$-en medio de la guerra de Sucesión- llevaron a la institucionalización definitiva del Real Cuerpo de Ingenieros en los nuevos Ejércitos Borbónicos y la fundación del Colegio de Barcelona, de donde ya en adelante saldrían formados los nuevos oficiales de ingenieros de la Monarquía. ${ }^{56}$ En este proceso no podemos olvidar que fue determinante la conexión del centro bruselense con el ingeniero militar Prospero Verboom ${ }^{57}$ en quien Felipe $\mathrm{V}$ depositó la confianza para el inmediato futuro del nuevo Real Cuerpo de Ingenieros español.

Con respecto a los artilleros no podemos hablar de paralelismo cronológico con los ingenieros en su institucionalización orgánica y docente, en el proceso de formación de los nuevos ejércitos permanentes, pues se dilataron las reformas y hubieron de esperar al reinado del tercer Borbón. La artillería sostenida con reglamentos monográficos ${ }^{58}$ para ir regulando lo que en un futuro sería su nueva orgánica, con Regimiento propio desde 1710 mandado por el Coronel Marcos Araciel ${ }^{59}$, sin embargo quedó a la espera de sus reformas definitivas hasta la llegada de Carlos III al trono que dinamizó su creación y organización para lo que trajo desde Nápoles al Conde de Gazola quien allí fue Director General de Artillería. ${ }^{60}$ La elección del artífice de las reformas artilleras estuvo clara para el monarca por la feraz experiencia napolitana conjunta. Y cabe señalar que la llegada del Conde de Gazola a España, uno más de los italianos del Rey ${ }^{61}$, definitivos en su primera etapa de gobierno, no obedecía únicamente a la fundación de un centro docente único para la formación de los futuros oficiales de artillería, a la fundación del Colegio Militar que dirigió hasta su muerte. Era un proyecto de mayor calado para el ejército y para la Monarquía.

La empresa presentaba mayor complejidad, su vertebración debía atender a tres planos diferentes pero interrelacionados, claves para el progreso de la Monarquía. Como desarrollé en un trabajo reciente, aquí tenemos que hablar de una empresa de Estado al más alto nivel, prioritaria para la Monarquía. Los futuros oficiales de artillería debían dominar las destrezas necesarias de la praxis artillera que había ido ganando en complejidad por su base científica, pues de la práctica empírica del tiro artillero más tradicional se había llegado a un momento en que era obligado estudiar matemáticas, física - para Gazola clave para la artillería- geometría, estática, balística, química... Muchas de ellas, disciplinas emergentes desde la revolución científica del siglo anterior, que tuvieron presencia ya en el plan de estudios del Colegio de artillería de Segovia desde su fundación en 1764, en mayor o menor proporción, según el momento. ${ }^{62}$

56 CAPEL, H.: "Construcción del estado y creación de Cuerpos profesionales científico-técnicos: los ingenieros de la Monarquía Española en el siglo XVIII”, en CÁmAra, A., CoBos, F. (eds.): Fortificación y frontera marítima. Actas del Seminario Internacional celebrado en Ibiza, Ibiza, Ayuntamiento de Ibiza, 2003. Se ha consulta la edición de Scripta Vetera.

57 CAPEl, SÁnchez, MoncAda, op. cit. (nota 6).

58 Uno de los primeros editados y de mayor contenido es el Reglamento y Ordenanza para la más acertada y puntual dirección de mi artillería, 1710.

59 Archivo Histórico Nacional (AHN), Estado, leg. 740. Borrador manuscrito del proyecto de reglamento de creación del Regimiento dela Real Artillería, 1710.

60 Herrero Fernández-Quesada, op. cit. (nota 7).

${ }^{61}$ MAFFI, D.: "Al servicio del Rey: la oficialidad aristocrática de "nación" italiana en los ejércitos borbónicos (1700-1800)", Cuadernos de Historia Moderna. Anejo X (2011), pp. 103-121.

62 Se han analizado los planes de estudio exhaustivamente en Herrero Fernández-Quesada, M. ${ }^{a}$ D.: "El Real Colegio de Artillería. De la fundación a la consolidación de un modelo de centro docente militar y científico- 
Pero, la innovación educativa artillera se inserta en un proyecto más amplio, en el contexto de una empresa de estado prioritaria para la Corona que reunía tres planos de actuación interrelacionados que debía engarzar desde 1760 el ya Teniente General Félix Gazola. ${ }^{63}$ La fundación de un centro docente tal, no podía realizarse sin un marco orgánico y, aún no se había abordado. De ahí que el piacentino empezara su gestión poniendo los cimientos, organizando definitivamente el Real Cuerpo de Artillería lo que se oficializó con la publicación de un texto constitutivo ya clásico en el proceso de la nueva planta artillera ${ }^{64}$, el Reglamento de Nuevo Pie en $1762^{65}$ donde se volcaron las reformas artilleras, diseño, orgánica, procedimientos y mapa del sitio del nuevo Real Cuerpo. En aquella ordenanza queda cerrado el mapa orgánico del Real Cuerpo de Artillería, incluso ya se recogía la formación de una Compañía de Caballeros Cadetes en el quinto departamento de artillería, que tendrá su desarrollo ordenancista en textos posteriores. ${ }^{66}$

El proyecto de Gazola tenía más derivadas de lo que en principio se puede presumir, porque el Colegio, su diseño, su ideario docente y plan de estudios no solo estaban encaminados a promover oficiales excelentes en la práctica artillera en campaña, sino que se planteó para formarlos paralelamente como ingenieros industriales, por las competencias que la Monarquía les reservaba en un futuro muy cercano. Esta es la clave del nuevo modelo de formación científico-técnica de los Cadetes de artillería ${ }^{67}$ Históricamente los artilleros estuvieron implicados de facto en la industria artillera, en la fabricación de los recursos necesarios para el buen desempeño de su profesión, recursos obtenidos por tradición por el sistema de asientos otorgados a empresarios, cada vez era más oneroso el precio de la guerra. ${ }^{68}$ Los recursos y el abastecimiento a los ejércitos siguieron gestionándose por el procedimiento de asientos, desde los uniformes a los víveres, según el modelo del Contractor State, trabajado por el grupo de investigación que coordina Rafael Torres. ${ }^{69}$ En el siglo XVIII la industria militar igualmente había ganado en complejidad tecnológica y la fundición de bocas de fuego o

Técnico", Revista de Historia Militar, volumen extraordinario (2014),pp.73-133; Herrero Fernández QuesadA, op. cit. (nota 41), pp. 299-320; Herrero Fernández Quesada, M. ${ }^{a}$ D.: "The Education of the Officer Classes in the 18th centuries", en Martínez Ruíz, E., Torrejón Chaves, J. (coords.): Spain and Sweden. Encounters throughout History. The Army and the Navy in Sapin and Sweden in a period of change (1750-1870), Cádiz, Fundación Berndt Wistedt y Universidad de Cádiz, 2001, pp. 235-262; Herrero Fernández-Quesada, M. ${ }^{a}$ D.: "Consideraciones en torno a la enseñanza artillera en el siglo XVIII. La proyección científico-técnica de los artilleros", en Giménez, E., Balaguer, E. (eds.): Actas del Congreso Ejército, Ciencia y Sociedad en la España del Antiguo Régimen, Alicante, Instituto de Cultura Juan Gil-Albert, 1995, pp. 407-433; Herrero FernándezQUESADA, op. cit. (nota 44).

63 Archivo General de Simancas (AGS), Guerra Moderna (GM), leg. 3. Expediente Personal del Conde de Gazola y nombramiento de Teniente General

${ }^{64}$ Una aproximación biográfica en Herrero Fernández-Quesada, M. ${ }^{a}$ D.: "Gazola, Félix", en Diccionario biográfico español, Madrid, Real Academia de la Historia, 2009, volumen XXII, pp. 667-672.

${ }_{65}$ AGMS, sección $2^{\mathrm{a}}$, división $8^{\mathrm{a}}$, leg. 10. Reglamento de nuevo pie en que S.M. manda que se establezca el Real Cuerpo de Artillería, Madrid, Imprenta de A. Marín, 1762.

66 BAAS. Ordenanza de SM para el Real Colegio Militar de Caballeros Cadetes de Segovia. s.i, 1768

67 Herrero Fernández-QuesadA, op. cit. (nota 7).

68 ToRres SÁnchez, R.: El precio de la guerra: el Estado fiscal-militar de Carlos III, Madrid, Marcial Pons, 2013.

69 TORRES SÁNCHEZ, R.: Military Entrepreneurs and the Spanish Contactor State in the Eighteenth Century, Oxford, Oxford University Press, 2016; véase también Torres SÁnchez, R.: "Los Cinco Gremios Mayores y la provisión de víveres al ejército español en el siglo XVIII", Studia Histórica. Historia Moderna, 34 (2012), pp. 407-432; ToRres SÁNCHEZ, R.: "Administración o asiento. La política estatal de suministros militares en la Monarquía española del siglo XVIII”, Studia Histórica. Historia Moderna, 35 (2013), pp. 147-182. 
sus municiones se alejaba cada vez más de los métodos empíricos de los diestros fundidores del pasado. ${ }^{70}$

De ahí que, en los planes del reformismo militar para la artillería, impulsados por la Monarquía y ejecutados por Gazola, el Colegio y los oficiales allí formados iban a ser una herramienta imprescindible para pasar a dirigir la industria militar en España, puesto que se fijó como objetivo estatalizar un sector tan importante para el estado moderno, poniéndolo en manos de oficiales formados en aquel centro científicotécnicamente que, dominando todos los procedimientos fabriles del ramo, fueran capaces de incorporar las novedades tecnológicas más recientes, ya implementadas en Europa. Con esto, se podría conseguir una de las aspiraciones más perseguidas por las monarquías europeas en el XVIII, la autonomía, el autoabastecimiento de recursos y materiales bélicos para sus Reales Ejércitos. Ante un reto de tal envergadura, Gazola -siempre buscando el asesoramiento y apoyos adecuados- engarzó las reformas artilleras para que estos tres planos, orgánico, formación y actividades industriales interactuasen, se retroalimentasen en el nuevo Real Cuerpo de Artillería Borbónico. La nueva planta artillera fue un proyecto de estado propio del siglo, del momento, del reinado, y de los actores implicados, en el que se articula innovación orgánica, docente e industrial. ${ }^{71}$

Así las cosas, en la nueva política educativa para los ingenieros y artilleros, la base técnico-científica de los Cuerpos Facultativos borbónicos es indiscutible y condiciona las reformas de la enseñanza militar en el siglo XVIII. Las investigaciones sobre el Colegio de Barcelona para los ingenieros desde Felipe V, las escuelas de Cádiz y Barcelona para los artilleros hasta Fernando VI, y el Colegio de Segovia con Carlos III, permiten hablar sin paliativos de innovación educativa, y exitosa. Nuevos planteamientos y criterios docentes para la enseñanza de la futura oficialidad, amplio elenco de materias científico-técnicas, impartidas por un claustro de profesores de altura en busca de la excelencia docente, sustanciada en sus ambiciosos planes de estudio, en sus nuevas metodologías docentes, y en la introducción de los manuales de texto elaborados por los profesores en un trabajo casi de sastrería, a la medida de necesidades, metas y objetivos.

En este sentido y para los ingenieros militares, fue determinante la gestión de Verboom $^{72}$ combatiente en la Guerra de Sucesión y, a la vez, artífice de la arquitectura orgánica y formativa de Real Cuerpo de Ingenieros. ${ }^{73} \mathrm{Su}$ relación con la antigua Academia de Bruselas, y con el propio Felipe de Anjou marcaron las reformas y los elementos de continuidad, que determinaron el éxito. De la misma forma, simplemente recordar que la etapa como Director de un personaje como Mateo Calabro ${ }^{74}$ ya nos habla de consolidación de estructuras y procedimientos docentes. Y en la misma línea de continuidad, cabría evocar los años de Lucuce en la academia de Barcelona y la edición de su libro de texto Principios de fortificación ${ }^{75}$-inspirado en la prolífica

70 Herrero Fernández Quesada, “Artillería. Evolución histórica de los materiales”, en Aproximación ..., op. cit. (nota 53), pp. 1127-1142.

71 Herrero Fernández Quesada, op. cit. (nota 7).

72 AGMS, sección $1^{\mathrm{a}}$, subsección célebres, caja 139, expediente 2. Expediente Personal del Teniente General Próspero Verboom.

73 Capel, SÁnchez, Moncada, op. cit. (nota 6).

74 Carrillo de Albornoz, J.: "Los ingenieros. Fortificación en España y Ultramar", en Iglesias, C. (coord.): Historia militar de España. Edad Moderna. III. Los Borbones, Madrid, CEHM-Real Academia de la Historia, Ministerio de Defensa, 2014, pp. 209-230.

75 Lucuce, P.: Principios de fortificación que contienen las definiciones de los términos principales de las obras 
tratadística de Medrano para el estudio de los alumnos de Bruselas- que, en breve, se constituye en un referente de manual de colegio militar o más bien en un modelo. La esencia de la profesión de los ingenieros militares, el arte de la fortificación -que bebía de la notable tradición tratadística en los dos siglos anteriores- se empezó a estudiar por los alumnos también en los libros de texto que incorporaban las últimas tendencias y modelos en arquitectura militar, con una estructura editorial y un lenguaje pedagógico sin precedentes, muy propios del siglo. ${ }^{76}$

En la misma línea, pero ya en la segunda mitad del XVIII, para los artilleros la producción propia de manuales también se incorporó a las innovaciones metodológicas y docentes del Real Colegio fundado en 1764 por Gazola. El primero de aquellos textos salido de la pluma del abate Pedro Giannini ${ }^{77}$, matemático italiano y Jefe de Estudios del Colegio ${ }^{78}$ quien lo dio a la imprenta de Antonio Espinosa de los Monteros para editar en tres tomos en 1780 y el tercer tomo de geometría y prácticas (lo que es una novedad en toda regla) en $1784 .^{79} \mathrm{El}$ segundo de los libros de texto de referencia para los alumnos de Segovia fue el Tratado de Artillería de Tomás Morla ${ }^{80}$, primer manual de la profesión editado para el estudio de los Cadetes alumnos, en tres tomos que desde su primera edición en 1784 se convirtió en todo un clásico de la ciencia artillera, no solo en España, sino en Europa, buscado y consultado por artilleros europeos que lo incorporaron a los anaqueles de las bibliotecas de sus respectivas academias. Napoleón mismo a su llegada a España, ilustra el interés que suscitó y la valoración del tratado en la profesión requisando todos los ejemplares depositados en la biblioteca del Colegio artillero. ${ }^{81}$ Sin ejemplares del tratado al final de la Guerra de Independencia, la vigencia de esta emblemática obra para el aprendizaje de la ciencia artillera perduró en el nuevo siglo, pues se publicó en edición revisada y actualizada en contenidos por el matemático y profesor del Colegio del que fue Jefe de Estudios, Juan Manuel Munárriz. Manuales, pero también tratados clásicos de la historia de la artillería. ${ }^{82}$

La importancia que le dio la Monarquía y sus Ministros a los centros docentes militares de la Armada y los Cuerpos Facultativos se demuestra en la política de impulso y generosidad económica que les amparó, y se encuentra reconocida abiertamente en numerosos textos de la segunda mitad del XVIII. En este sentido, puede ser pertinente traer a colación la alusión a esta política de prioridades que inserta el padre Eximeno en su lección de apertura del Colegio Artillero donde puso de manifiesto la predilección del Monarca por el centro al instalarlo en "el mejor alcázar de su reino", y al dotarlo con esplendidez. Pero, más aún, en el marco del reformismo militar el jesuita enfatizó explícitamente ante los Caballeros Cadetes "la incompa-

de plaza, y de campaña, con una idea de la conducta regularmente observada en el ataque, y defensa de las fortalezas. Dispuestos para la instrucción de la juventud militar, Barcelona, Imp. T. Piferrer, 1772.

76 García Hurtado, op. cit. (nota 26); Herrero Fernández-Quesada, op. cit. (nota 54).

77 Giannini, P.: Curso matemático para la enseñanza de los Caballeros Cadetes del Real Colegio Militar de Artillería, Segovia, Imp. Espinosa, 1782-1795.

78 Navarro Loidi, J.: Don Pedro Giannini o las matemáticas de los artilleros del siglo XVIII, Segovia, BCA, 2013.

79 Giannini, P.: Prácticas de geometría y trigonometría para la enseñanza de los Caballeros Cadetes del Real Colegio Militar de Artillería, Segovia, Imp. Espinosa, 1784.

80 Morla, T.: Tratado de Artillería para el uso de la Academia de Caballeros Cadetes de Artillería, Segovia, Imp. Espinosa, 1784-1786, en tres tomos, al que se añadirá el Libro de Láminas, Madrid, Imp. Real, 1803.

81 Herrero Fernández-Quesada, M. ${ }^{a}$ D.: Ciencia y milicia en el siglo XVIII. Tomás de Morla, artillero ilustrado, Segovia, PAS, 1992.

82 En la segunda edición de la obra tras la Guerra de la Independencia, se editó un volumen de Explicación a las láminas, Segovia, Imp. Espinosa, 1816. 
rable firmeza con que el Ministro de la Guerra, atento a fomentar el nervio de la Monarquía, fomenta vuestro establecimiento". ${ }^{83}$

No podemos olvidar que el monarca era Carlos III, el Ministro Esquilache y el Director General de Artillería y del Colegio, el Conde de Gazola (el equipo italiano) quien, está documentado, que contó con apoyos tan notables como el del Ingeniero General Sabatini en la proximidad y estrecha colaboración cotidiana, y como el del veterano ministro Tanucci, en la distancia. De hecho, la aportación de Sabatini resultó ser decisiva para la construcción de la Fábrica de Armas de Toledo, una de las aspiraciones industriales del Conde que vino de Italia con referencias preconcebidas. ${ }^{84}$ Fueron muchas e importantes, por tanto, las inversiones pero también las expectativas creadas en torno a esa futura oficialidad, que nada menos debía erigirse en "nervio de la Monarquia". En su discurso, Eximeno apuntaba que la innovación docente propuesta para el nuevo colegio artillero, se completaba integrando en los planes de formación, los valores, propios del siglo y de la milicia, e inculcándolos en los jóvenes alumnos. Tanto el jesuita en su lección como el canónigo Clemente Peñalosa (tan vinculado al Colegio y a la profesión artillera) a finales de siglo lo entendían como imprescindible "la táctica militar forma soldados, el honor héroes". ${ }^{85}$ En ambos textos se recupera el concepto de héroe de la antigüedad clásica, reformulado para los nuevos tiempos históricos, de tal manera que el Jefe de Estudios aportaba en su primera lección el perfil del oficial de artillería del colegio, quien sería "un gran matemático, un histórico, un héroe". ${ }^{86}$

Además en el proceso de renovación de la enseñanza militar, esta política docente fidelizaba incondicionalmente a aquellos oficiales y futuros cuadros de mando, imbuidos en sus años jóvenes del espíritu reformista y de progreso de la Monarquía, con el que empatizaron tempranamente hasta el punto de hacerlo suyo y de trabajar por él, en esa línea de progreso optimista que vertebraba el reformismo borbónico, en sus diferentes trayectorias profesionales.

No es casualidad por tanto, que al analizar el grado de implementación de las Ordenanzas y reglamentos, los Cuerpos Facultativos se presentan como unas de las luces del reformismo militar. Con estos mimbres que tejieron la política de innovación docente, no es casual tampoco que encontremos en los Cuerpos Facultativos de Ingenieros y Artillería, el máximo grado de literalidad en el cumplimiento de la Ordenanza. A esto contribuyó, no en vano, su menor número de componentes y la firme implantación y aceptación de la llamada "escala cerrada" en los ascensos por antigüedad, sin dejar resquicios para la promoción no reglada.

Y en el proceso de renovación y cambios en el modelo docente militar, en busca de Minerva, colegios, planes de estudio innovadores, profesorado altamente cualificado y la introducción de manuales como herramienta para la enseñanza militar, son lugares comunes que compartieron las Armas Sabias de los Reales Ejércitos Borbónicos en el XVIII. De ahí que sea posible afirmar que el éxito y la excelencia

83 Eximeno, A.: Oración que en la abertura de la Real Academia de caballeros Cadetes del real Cuerpo de Artillería nuevamente establecida por S.M. en el Real Alcázar de Segovia, dixo el Padre Antonio Eximen, de la Compañia de Jesús. Profesor Primario de dicha Academia, en el día 16 de mayo de 1764, Madrid, Imp. Eliseo Sánchez, 1764. Ver también Pardo Canalis, E.: El Padre Eximeno, Profesor Primario del Real Colegio de Artillería de Segovia, Segovia, Patronato del Alcázar de Segovia, 1987.

84 Herrero Fernández-Quesada, op. cit. (nota 7).

85 Peñalosa, C.: El honor militar, causas de su origen, progresos y decadencia, o correspondencia de dos hermanos desde el exercito de Navarra de SMC, S. 1., Oficina de D. Benito Cano, 1795.

86 EXIMENo, op. cit. (nota 83). 
acompañaron en toda la centuria a las reformas militares relativas a los Reales Cuerpos de Ingenieros y Artillería.

Pero aunque en la cuenta de resultados manda el haber sobre el debe, con un balance claramente positivo, no podemos dejar de señalar que nada es perfecto, que también hubo fallas, grietas puntuales que delatan cómo las expectativas creadas en torno a todo este proceso no se vieron cubiertas al cien por cien, como se esperaba. En este estudio que transita del reformismo al mito, cabe señalar que en nuestra aportación localizamos el Talón de Aquiles de las armas sabias, por cierto en el mismo lugar que para el resto del ejército borbónico. Ingenieros y artilleros encontraron su espacio de confort en lo científico-técnico, pero en la praxis, donde se debía demostrar su eficacia, en campaña, que es donde había que recoger realmente los réditos de tantos esfuerzos invertidos en el nuevo modelo militar, aparecen los fracasos. Al respecto, traemos únicamente aquí dos datos indicativos.

Con respecto a los Ingenieros que tienen tanto en su haber al realizar el balance del XVIII no solo en España sino en Ultramar con el amplio plan de renovación de las defensas ${ }^{87}$, cabría reflexionar en torno a la fortaleza de San Fernando de Figueras y sus circunstancias. Una fortificación de nueva traza, ejemplo de proyecto ilustrado, con medios, ingenieros del primer nivel, la más grande de Europa y que sin embargo fracasó en los momentos críticos para los que había sido diseñada. ${ }^{88}$

Igualmente, por lo que concierne a los artilleros, con una formación de élite en los años pasados en el Seminario Militar de Segovia, con un imponente elenco de oficiales útiles a la nación que desempeñaron profesionalmente destinos al más alto nivel y en las diferentes áreas como directores de fábricas, Capitanes generales, oficiales del despacho, científicos o Virreyes en América. Sin embargo, la prueba del algodón de sus capacidades también presenta algún claroscuro. Los dos retos tecnológicos que debían afrontar, dominar y superar en la segunda mitad del XVIII para impulsar la industria militar, resultaron ser dificultosos y dieron lugar a un retraso temporal con respecto a Europa, en la asunción de estos procedimientos tecnológicos imprescindibles para el desarrollo de la siderurgia y de las nuevas bocas de fuego, al que finalmente se llegó. ${ }^{89}$

\subsection{El debate teórico-práctico. Las crisis en el Colegio Artillero, calibrando contenidos}

Sin embargo, y a pesar de estos problemas tecnológicos, la clave de los éxitos del reformismo borbónico en los Cuerpos Facultativos estuvo en la política de innovación educativa, en las reformas para la instrucción de los futuros cuadros de mando. En la Ilustración, la formación era la base, la buena educación. Y volviendo al debate teórico-práctico referido a los contenidos de la enseñanza, estuvo sobre la mesa y preocupó a la Monarquía hasta el final de la centuria. Así lo demuestran textos de la

87 Andrés Herrero, M.: "Ultramar. La artillería de costa extrapeninsular. Amenaza permanente y despliegue de posiciones”, en La artillería de costa española, Madrid, Ministerio de Defensa, 2014, pp. 175-238.

88 Díaz Capmany, D.: El castillo de San Fernando de Figueres. Su historia, Barcelona, Generalitat de Cataluña,

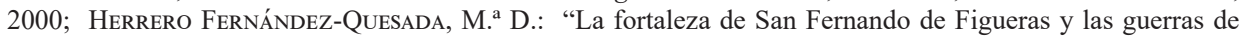
los siglos XVIII y XIX”, en CANal, J. (ed.): Figueras, capital de la República: 1 de febrero de 1939, Madrid, Congreso de los Diputados, 2010, pp. 31-44.

89 Herrero Fernández-Quesada, M. ${ }^{\text {a D }}$.: “Antonio ELORZA AGUIRRE”, en Diccionario biográfico español, Madrid, Real Academia de la Historia, 2009, tomo XVII. 
época, de la segunda mitad del siglo XVIII que tienen que ver con la enseñanza militar y su institucionalización en los cuerpos facultativos, y que tienden a demostrar la necesidad de cursar la academia y aprender ciencia y técnica junto a las materias propiamente militares. En este estudio, lo centraremos en el Colegio artillero y en los oficiales allí promovidos. No es casual ni anecdótico que el 16 de mayo de 1764 fecha de la inauguración solemne del Real Colegio de Artillería, su Jefe de Estudios el matemático padre Antonio Eximeno subtitulara la lección de apertura de aquel centro docente así de explícitamente: "Sobre la necesidad de la teórica para desempeñar en la práctica el servicio de SM". ${ }^{90} \mathrm{El}$ jesuíta recoge la discusión que enfrenta a la instrucción meramente práctica o empírica del pasado con la contemporánea de fuerte base teórica y científica. Su lección magistral es una sintética defensa del nuevo modelo de formación militar, donde dedica una buena parte a ponderar el estudio de las ciencias para poder desempeñar en el futuro aquellos alumnos la profesión militar y artillera. El tiempo, en breve, le dio la razón con respecto al colegio artillero. La fórmula exitosa del ideario docente del centro acertó a la hora de calibrar contenidos y materias e insertar en su completo plan de estudios teóricos, la práctica militar y artillera $^{91}$, sin la que sería también imposible mandar una batería de cañones. ${ }^{92}$

Eximeno en su lección magistral de apertura de la academia, argumentaba acudiendo a los clásicos, griegos preferentemente, pero también a los contemporáneos europeos que marcaban tendencia en el ámbito militar cuando afirmaba:

el arte de la guerra, dice Federico Rey de Prusia, se debe estudiar como qualquiera otra ciencia; se deben estudiar sus principios y gobernarse en la práctica de ellos. Es cierto que estos principios deben estar apoyados en la misma experiencia; pero ningún hombre es capaz de hacer por si las experiencias necesarias para hacer un solo principio. ${ }^{93}$

El matemático en su discurso inaugural del Colegio, dirigiéndose a los Cadetes, se hace eco del debate que aún enfrentaba a mediados del XVIII el modelo de instrucción meramente práctica o empírica del pasado con el de fuerte base teórica y científica. A lo largo del siglo se mantendrá la discusión con más o menos intensidad, según el momento, no solo en el seno de los reales ejércitos, sino en el propio colegio artillero, centro docente militar rápidamente consolidado y de prestigio en el que, sin embargo, y a pesar de los éxitos de su trayectoria marcada por un ideario docente, hubo discrepancias conceptuales internas. En las Actas del Consejo Escolar del Colegio ${ }^{94}$, ya se reflejan estos debates, sobre todo cuando se cuestiona la orientación de la enseñanza por parte del Jefe de Estudios que a la vez era quien ostentaba la catedra de matemáticas, eje vertebral de la formación de los artilleros en Segovia.

Y con sucesivos Jefes de estudios, cuando se hicieron las gestiones para cubrir la plaza y Gazola buscó a Ginanni, los profesores del Colegio, en el seno de su Consejo Escolar se cuestionaban la utilidad de tanto contenido matemático y científico en el plan de estudios de los artilleros ${ }^{95}$. En las últimas cuatro décadas del XVIII, en un

\footnotetext{
EXIMENO, op. cit. (nota 83).

Herrero Fernández-Quesada, op. cit. (nota 7).

Herrero FERnÁndeZ-Quesada, op. cit. (nota 41).

EXIMENO, op. cit. (nota 83).

Actas del Consejo..., op. cit. (nota 10). Sesiones recogidas en el tomo II.

NAVARRo LoIDI, op. cit. (nota 78).
} 
centro docente militar no solo emergente, sino ya de prestigio rápidamente reconocido, ciframos dos momentos de crisis y cuestionamiento del modelo formativo artillero de fuerte base científica, que coinciden y no por casualidad, con la vacante de la Jefatura de Estudios de la academia y las dificultades para su cobertura. No en vano, del Jefe de Estudios dependía la orientación del plan de estudios y la determinación del equilibrio de los contenidos científicos y teóricos con los prácticos.

La primera crisis se desencadena pronto, tras la salida del Colegio y de España del Padre Eximeno siguiendo la misma suerte que su Orden. ${ }^{96}$ Primer Profesor Primario del Colegio que, en comunión con el Conde de Gazola, su Director fue determinante para la cátedra de Matemáticas de la academia y el tono científico técnico de la misma. En 1767 Eximeno se exilia y -a la luz de la documentación- bien podemos afirmar que el Conde de Gazola como Director no logró cerrar la crisis hasta el nombramiento de Cipriano Vimercati ${ }^{97}$ con quien las aguas volvieron a su cauce temporalmente en la línea de los planteamientos docentes fundacionales, llegando incluso a elaborar su propio Curso matemático para la enseñanza de los alumnos del colegio que, lamentablemente, no se llegó a imprimir.

En medio, hubo interinidades como la del capitán Lasso de la Vega ${ }^{98}$ con un alto perfil y trayectoria docente consolidada en la enseñanza artillera pero que no logró encauzar definitivamente al claustro, siendo recurrentes las discusiones en el seno del Consejo escolar que, presidido por Gazola, aún cuestionaba la necesidad de tanta matemática en el plan de estudios. ${ }^{99}$

El segundo momento crítico en el que el modelo e ideario docente del colegio se cuestionó severamente por parte del claustro fue precisamente en los años que siguieron a la marcha de la Jefatura de Estudios de Vimercati que se pasó al servicio en la Armada. ${ }^{100} \mathrm{Y}$ volvemos a un periodo de discusiones enfrentadas que no se resuelven hasta que en un proceso de selección ciertamente dilatado, Gazola -casi al final de sus días- resuelve con solvencia y elige de nuevo a un matemático religioso, el abate Giannini que con mano firme en adelante desempeñó la Jefatura de Estudios y mantuvo el tono científico técnico de la enseñanza artillera, incluso tras la muerte en 1780 del Conde, su primer Director y fundador, y la llegada de su sucesor, el Conde de Lacy. ${ }^{101}$ Con Giannini, además - como ya se ha indicado anteriormente- se colmó la aspiración de ver editado el primer manual de texto de matemáticas y geometría, específicamente elaborado para la formación de los Caballeros Cadetes en Segovia.

Sin embargo, avanzando el siglo, el sentir general manifestaba respaldo a la enseñanza de los artilleros de fuerte fundamentación científico-técnica, sin distinción de generaciones por cierto, como se demuestra en un erudito e interesante impreso con el que cerramos argumento. Editado tan solo diez años después de la puesta en marcha del colegio de Segovia, lo escribe un veterano oficial, el Capitán Gregorio Menéndez Valdés, dirigido a su nieto, Cadete en el Colegio artillero. En su opúsculo, reiteradamente reconoce como indispensable el estudio científico-militar para el des-

\footnotetext{
96 Pardo Canalis, op. cit. (nota 83).

97 AGMS, sección $1^{\text {a }}$, división $1^{\text {a }}$, leg. B-2930. Expediente Personal de Cipriano Vimercati. Su trayectoria como Jefe de Estudios se ha seguido por las Actas del Consejo Escolar... ya citadas en notas previas. Véase también Herrero Fernández-Quesada, op. cit. (nota 62).

98 AGMS, sección1 ${ }^{\mathrm{a}}$, división 1a, leg. L-400. Expediente personal de Lorenzo Lasso de la Vega.

99 Actas del Consejo..., op. cit. (nota 10).

100 Herrero Fernández-Quesada, op. cit. (nota 62).

101 Herrero FernándeZ-Quesada, op. cit. (nota 41).
} 
empeño práctico de la profesión en el futuro, pues en aquel centro docente, afirmaba, sería “donde los alumnos de Minerva, salgan después para Martes en la Campaña". ${ }^{102}$

\section{Los artilleros o la rentable educación de Marte}

La discusión sobre la formación de los oficiales de acuerdo con el nuevo modelo docente militar, estaba servida, a pesar de que los tempranos réditos de una formación científico-técnica de la oficialidad en la Marina, ingenieros y artilleros, pronto fueron del dominio público. Réditos múltiples y varios, que encontramos en primera instancia en la asunción de misiones y comisiones multidisciplinares por parte de aquellos, de gran utilidad para la Monarquía y el progreso de España, que acudirá a este grupo profesional y social para comisiones específicas. Y, finalmente, veremos la rentable educación de Marte siguiendo la trayectoria de oficiales de artillería transitando de las actividades científicas al desarrollo de la Economía Política.

\subsection{Versatilidad profesional. Artilleros y el ingeniero Betancourt espiando por Europa}

En la virtual cuenta de resultados que mide la rentabilidad de la educación de Marte en los Reales Ejércitos del XVIII, manda el haber sobre el debe. La máxima expresión de cómo marinos y militares de los cuerpos facultativos se constituyeron en elementos imprescindibles para el progreso científico-técnico y militar de la Monarquía $\mathrm{y}$, por tanto, en canalizadores de la introducción y el fomento de la ciencia y la nueva técnica en la España del XVIII, podría ser la aceptación para asumir por su parte de misiones que bien podemos situar en un plano absolutamente distante de la milicia, como el espionaje. ${ }^{103} \mathrm{La}$ formación de marinos y militares ilustrados les convertía en perfectos y cualificados agentes de observación en el exterior, y las raíces de su lealtad profesional, en una garantía de seguridad sin competencia.

Desde la década de los 80 del siglo pasado la investigación sobre los colegios, academias y los oficiales y el seguimiento de sus trayectorias profesionales y destinos confesables e inconfesables han permitido constatar lo que será una de sus señas de identidad en el XVIII, la dedicación de algunos de ellos al espionaje industrial por la Europa de la Ilustración comisionados por el gobierno. Esos oficiales y marinos formados en sus academias para que fueran "el nervio de la Monarquía" (Eximeno dixit), desde Felipe $\mathrm{V}$ ejercen de tales, y entran a formar parte de una selecta y discreta red de españoles por Europa en el ejercicio de "comisiones facultativas" pues así aparecen denominadas en la documentación, como ya trabajaron Peset y Lafuente, y Helguera. ${ }^{104}$

102 Menéndez Valdés, G.: Avisos históricos, y politicos de el Capitán D. Gregorio Menéndez Valdés, Sr. De San Andrés de Cornellana, vecino y regidor perpetuo de la muy noble villa, y concejo de Gijón, en el Principado de Asturias, a D. Miguel Gregorio, su nieto, Caballero Cadete en el Real Colegio de Artillería del Real y Militar Alcázar de Segovia, a quien los dedica, Madrid, en la Oficina de la Viuda de Manuel Fernández, 1774, p. 4.

103 Lafuente, A., Peset, J. L.: "Política científica y espionaje industrial en los viajes de Jorge Juan y Antonio de Ulloa", Melanges de la Casa de Velázquez, XVII (1981), p. 234; y PeSET ReIG, J. L. (dir.): Historia de la ciencia y de la técnica en la Corona de Castilla, Siglo XVIII, Valladolid, Junta de Castilla y León, Consejería de Educación y Cultura, 2002, vol. 4.

104 Helguera, J.: "Las misiones de espionaje industrial en la época del Marqués de la Ensenada, y su contribución al conocimiento de las nuevas técnicas metalúrgicas y artilleras, a mediados del siglo XVIII", en Actas del II Congreso de Historia de la Ciencia, Valladolid, Junta de Castilla y León, 1987, pp. 671-696. 
Con Felipe $\mathrm{V}$ y sus ministros se diseña el modelo de viaje facultativo y consolida por sus buenos resultados y utilidad política. En Madrid se fijaban los objetivos y destinos de los comisionados para, finalmente, elaborar un cronograma y un itinerario fijado de antemano que debían cubrir con eficacia desde la discreción. De ahí que, estos marinos y militares viajaran de incógnito y de paisano por Europa visitando países, ciudades, establecimientos fabriles, unidades...con el fin de recabar información útil para la Monarquía, los ejércitos y la Armada, la ciencia y la técnica, en definitiva, para el progreso de España. ${ }^{105}$ En buena lógica, entre sus herramientas de trabajo, se utilizaba y con frecuencia el soborno neutralizador del secretismo y de las medidas de seguridad con que se protegían ante los extranjeros especialmente en las industrias y fábricas militares o los arsenales. Todas sus observaciones e informes debían ser remitidos a la Corte por la vía reservada y los canales diplomáticos, pero también obligatoriamente quedarían recogidos en sus impagables diarios de viaje.

Es conocido que los marinos Juan y Ulloa fueron pioneros, entre otras cosas porque -a pesar de las precauciones- Juan fue descubierto en Londres. Sin embargo en este estudio, nos parece de interés señalar que a su comisión en las islas y a la de Ulloa en Paris, hay que unir la desempeñada coetáneamente por otro marino, Juan de Lángara en Lisboa, las tres perfectamente coordinadas. ${ }^{106}$ Con un modelo de comisiones al extranjero ya contrastado por la experiencia de los marinos espiando en el eje LondresParis-Lisboa como base, con Fernando VI se continuó enviando comisionados a Europa, en un contexto político marcado por la neutralidad y la paz armada. Misiones a las que el inquieto Ensenada imprimió su propio sello, enviando en esos años a artilleros con diferentes resultados, en estricta aplicación de la máxima si vis pacem para bellum.

Sin embargo, interesa recordar aquí el viaje facultativo de dos artilleros que demuestra a la perfección la rentable educación de Marte que nos ocupa. Carlos III no era un advenedizo en la utilización de estas prácticas políticas, dominaba estos procedimientos. Como Rey de Nápoles y ya en España con la inestimable ayuda de sus ministros de la Guerra y del Conde de Gazola envío en comisión de espionaje industrial a dos artilleros que viajaron por las islas británicas y el continente siguiendo un meditado programa y anotando hasta los más nimios aspectos que pudieran ser de interés, prioritariamente enfocados a la industria militar y artillera. ${ }^{107}$ Los capitanes Guillelmi y Morla fueron comisionados y por fortuna se conserva el diario de viajes del segundo cuya factura y lectura nos hace tomar contacto con la Ilustración en estado puro, pues junto a la información relativa al espionaje industrial, incorporaban hasta el último dato o información, de la naturaleza que fuera, siempre que pudiera ser de utilidad pública. ${ }^{108}$

Pero lo que queremos destacar en este estudio del viaje por Europa de estos dos oficiales es la oportunidad del momento, trascendental y más que pertinente para la artillería, pues en Europa se transitaba del sistema Valliére al nuevo sistema Gribeauval, de artillería más ligera ${ }^{109}$, y la estrecha colaboración entre ingenieros y artilleros por Europa recabando noticias e informaciones para el progreso de la industria ar-

105 Herrero Fernández-Quesada, op. cit. (nota 81).

106 AGS, Marina, leg. 712. Correspondencia de Lángara con Ensenada, fechada en 1749.

107 HerRero FernÁndeZ-QuesAdA, op. cit. (nota 81).

108 BAAS. Morla, T.: Apuntes autógrafos. (1789-1790). Este manuscrito es su diario de viaje por Europa.


intervención", en Actas del III Congreso Internacional de Historia Militar, Zaragoza, Institución Fernando El Católico, 1994, pp. 421-432; Herrero Fernández-Quesada, M. ${ }^{a}$ D.: "Artillería. Evolución histórica de los materiales, en Aproximación..., op. cit. (nota 53), pp. 1127-1142. 
tillera. En relación con ello, en el Continente también se llevaba tiempo fundiendo artillería en sólido, abandonándose el procedimiento tradicional de fabricación de cañones en hueco, con el que se seguía fundiendo en la Península y, posiblemente el motivo principal de la organización de la comisión facultativa de los dos capitanes. Mientras, en España las fundiciones y los fundidores se mostraban resilientes a pesar de que se había contratado al padre de la nueva tecnología, al fundidor Jean Maritz ${ }^{110}$ y otros miembros de su saga que tenía el encargo de implementar el nuevo sistema y procedimientos en las fundiciones españolas. Su estancia, muy bien pagada, sin embargo estuvo marcada por un pulso sostenido con los oficiales de artillería destinados en las fábricas y reticentes a las ventajas de la fundición en sólido que procuraban eclipsar en las pruebas de resistencia a que se sometía a los cañones tanto en Sevilla como en Barcelona. Este será el primer reto tecnológico al que debían enfrentarse los oficiales de artillería del colegio, y motivo capital por el que se organizó este viaje de espionaje por Europa.

Además, relacionado con ello y muy vinculado a la industria artillera, hay que señalar que el incremento de actividades industriales en Inglaterra -ya inmersa en la revolución industrial- amenazaba con la deforestación. Ese mismo temor se cerniría en breve sobre los bosques españoles por lo que era urgente que los artilleros conocieran los nuevos sistemas de alimentación de los hornos con carbón mineral y no con carbón vegetal y especialmente su aplicación a la fundición de bocas de fuego, de cañones. Este será el segundo de los retos tecnológicos que más trabajo costó superar con destreza a los artilleros españoles, y el segundo motivo dinamizador del viaje de espionaje al extranjero. ${ }^{111}$

De aquella comisión al extranjero se extrajo información valiosa y variopinta, ya tratada con anterioridad. Sin embargo, aquí, en la cuenta de resultados de la educación militar en el XVIII, interesa destacar especialmente su aplicación al progreso técnico de la industria artillera y militar, la fase subsiguiente al viaje facultativo, la aplicación de los resultados del espionaje en la Península. El mapa de su itinerario por el extranjero, y la naturaleza diversa de las informaciones volcadas en el diario ejemplifican al detalle los réditos. Como consecuencia de aquella comisión, y aplicando las informaciones recogidas por Europa se trabajó en la maestranza de Barcelona ${ }^{112}$ sobre nuevos montajes y cureñas para las piezas de artillería y sobre el método de fundición de cañones de pequeño calibre en aplicación de lo observado por Europa, la artillería ligera.

Con respecto a la inteligencia del momento elegido para el viaje, cabe reparar en que la misión de espionaje se desarrolla en la década de los 80 , y cuando estos dos artilleros viajaron por Europa, no eran los únicos que hacían espionaje industrial, había un cierto tráfico de talentos trabajando en Francia. De hecho, desde 1785 un prometedor oficial de Ingenieros, Agustín de Betancourt ${ }^{113}$, estaba comisionado para estudiar en la Escuela de Caminos, canales y puertos, como un becado español más en la Francia de

110 Herrero Fernández-Quesada, M. a D.: “Materiales”, en Valdés Sánchez, op. cit. (nota 43), pp. 121-134.

111 Las últimas décadas del XVIII fueron un duro camino de aprendizaje a la hora de fundir alimentándolos hornos con carbón vegetal, y los resultados no eran los deseados, a pesar de la apertura de la Fábrica de Trubia donde se producirá finalmente el despegue de la siderurgia en sus altos hornos, los primeros de España, durante la gestión como director de Francisco de Elorza, Herrero Fernández-Quesada, op. cit. (nota 89).

112 En efecto, Tomás de Morla tras finalizar la comisión al extranjero llegó a Barcelona el verano de 1791 para aplicar sus conocimientos y la información recaba operando en la fundición y maestranza de aquella ciudad, AGMS, sección $1^{\mathrm{a}}$, división $1^{\mathrm{a}}$, leg. M- 4609. Expediente personal de Morla donde se conserva el epistolario al respecto con el Conde de Lacy.

113 AGMS, sección 1 ${ }^{\mathrm{a}}$, división 1 ${ }^{\mathrm{a}}$, leg. B-2217. Expediente Personal del ingeniero Agustín de Betancourt y Molina. 
la Ilustración. Su formación dio notables réditos a la Monarquía, pues a él se debe la factura del Gabinete de Máquinas del Buen Retiro ${ }^{114}$ y por fin la creación en España de la Escuela de Ingenieros de Caminos... Sin embargo en esta evocación del perfil de los espías uniformados del XVIII, soportes de actividades importantes y complejas, nervios sin duda de la monarquía, es preciso señalar aquí que, siendo un becado oficial en Paris, Betancourt también realizó trabajos de espionaje industrial en Francia para el adelantamiento de la industria artillera, coetáneos y complementarios a los de los dos artilleros, con quienes hubo fluída comunicación y estrecha colaboración.

En este trabajo, tres datos sobre las aportaciones de Betancourt al espionaje ilustrado bastarán para comprobar que el ingeniero español era más que un peón de la red informativa de la Monarquía en la última y vibrante década del reinado de Carlos III. En primer lugar recabó valiosa información que ilustró en un álbum de acuarelas de la fábrica de artillería de Yndret, establecimiento en el que se fundían piezas de hierro y del que, por fortuna se conserva la memoria y la iconografía que la acompaña. ${ }^{115}$ Por entonces y en el marco del proceso de reestructuración de las fábricas, la excelente de artillería de hierro para la Armada española que se fundía en Liérganes y la Cavada, pasó a ser responsabilidad de los marinos y ambos establecimientos se manifestaron insuficientes para la demanda de artillado de la Armada. ${ }^{116}$ Se presentó un problema por tanto de abastecimiento y posiblemente relacionado con los procedimientos de fundición. No fue menor el trabajo que a Betancourt se le encomendó desde Madrid aprovechando su estancia profesional en Francia. En la Corte preocupaba el autoabastecimiento de piezas de artillería de hierro para la Marina que por entonces ya eran insuficientes para artillar los barcos, de ahí su comisión de espionaje a Yndret complementaria a la información que recabó en Inglaterra Morla sobre las carronadas, piezas de hierro para la Marina que finalmente serían las que el Estado compró para reforzar el artillado de la Armada española. ${ }^{117}$

En segundo lugar, queremos recoger aquí que en 1785, antes de la llegada de los dos artilleros a Francia Betancourt realizó una memoria sobre la purificación del carbón ${ }^{118}$, en la línea de trabajo sobre el nuevo combustible para alimentar los hornos de las fábricas y fundiciones.

La tercera aportación de Betancourt colaborando con los artilleros a la hora de conseguir información para este sistema de armas en la Francia ilustrada tiene que ver con que también en aquellos años 80 del XVIII llegó a España por segunda vez,

114 Sigue siendo imprescindible para la aproximación a su figura el trabajo de RumeU DE Armas, A.: El Real Gabinete de máquinas del Buen Retiro. Una empresa técnica de Agustín de Betancourt. Con el facsímil de su catálogo y un estudio sobre las máquinas por Jacques Payen, Madrid, Fundación Juanelo Turriano, 1990.

115 Betancourt, A. de: Descripción del establecimiento de Yndrid, donde se funden y barrenan los cañones de hierro para la Marina Real de Francia. Manuscrito. Álbum de Acuarelas. Real Biblioteca del Palacio Real de Madrid (BP). Album IX/M/97.

116 Sobre las dos fundiciones santanderinas es ya un clásico de obligada consulta la obra de AlCALÁ-ZAmorA, J.: Historia de una empresa siderúrgica española: los altos hornos de Liérganes y La Cavada (1622-1834), Santander, Diputación Provincial, 1974.

117 Herrero Fernández-Quesada, M. ${ }^{a}$ D.: “Adquisición de "carronadas” para la Armada Española a finales del siglo XVIII", en Poder terrestre y poder naval en la época de la batalla de Trafalgar, Madrid, Ministerio de Defensa, 2006, pp. 643-649.

118 Betancourt, A.: Memoria sobre la purificación del carbón de piedra y modo de aprovechar las materias que contiene. Manuscrito inédito que sacó a la luz en un trabajo Bonet CorreA, A.: "Un manuscrito inédito de Agustín de Betancourt sobre la purificación del carbón”. Fragmentos, nos. 12, 13, 14, Madrid, Ministerio de Cultura, 1988, pp.279-285. 
el químico francés Luis Proust ${ }^{119}$, para en los años previos a 1792 abrir el Laboratorio de Chimia que vino a dirigir. ${ }^{120}$ Se dedicó al montaje puntilloso de aquel gabinete que iba a completar los conocimientos de química metalúrgica de los artilleros formados en el Colegio de Segovia. ${ }^{121} \mathrm{Si}$ las primeras décadas de andadura del Colegio consolidan la enseñanza de los contenidos matemáticos en el plan de estudios, las dos últimas décadas del XVIII representan la integración definitiva de la enseñanza de la nueva ciencia química, imprescindible en la formación de los futuros directores de las fábricas, especialmente la química metalúrgica. ${ }^{122}$ Pues bien, en esos años, Proust visitó fábricas y minas pero, sobre todo, se dedicó a la investigación fruto de la cual se editaron los ya clásicos en la historia de la ciencia Anales del Real Laboratorio $^{123}$, en dos tomos. Como profesor del claustro y en estrecha relación con la Sociedad Económica de Amigos de País (SEAP, en adelante) interesada sobremanera en la resurrección y dinamización de la industria textil segoviana y en proporcionar recursos para ello, Proust aportó trabajo y relaciones. Y es aquí donde Betancourt entró en escena.

De hecho, en una de las memorias de investigación de los Anales, pone de manifiesto su correspondencia con Betancourt y las gestiones que le encomendó para investigar el estado de la cuestión en Francia a la hora de conseguir determinados tintes y singularmente el azul de Prusia. Esta comisión fue una nueva contribución del ingeniero al espionaje que entrañaba dificultad sin duda, puesto que los procedimientos técnicos y fabriles estaban protegidos por el mayor de los secretismos. A pesar de ello, cumplió con ello con éxito, y envió los datos solicitados a Luis Proust.

En suma, la investigación en las comisiones de oficiales por la Europa del XVIII, ilustran al más alto nivel la rentable educación de Marte en los ejércitos permanentes borbónicos, singularmente de los oficiales de los Cuerpos Facultativos y su versatilidad profesional en los diferentes ámbitos y materias.

La inversión de tiempo, hombres, recursos y dinero en innovación educativa proporcionó réditos notables superando las expectativas puestas en esta política.

\subsection{Versatilidad profesional de los artilleros. De las ciencias a la nueva Economía Política}

Los artilleros formados en el Colegio de Segovia, el soporte, "el nervio de la Monarquía" y de los gobiernos en misiones complejas y de alta política, entendidas como trascendentes para el futuro y progreso de España. Pero en el contexto general del reformismo militar borbónico se proyectan potentes luces en el nuevo modelo y éxitos en la innovación educativa, y sin duda, casi en tiempo real se constata la

119 Herrero Fernández-Quesada, M. ${ }^{a}$ D.: Cañones y probetas en el alcázar. Un siglo en la historia del Real Colegio de Artillería de Segovia (1764-1862), Segovia, PAS, 1993; y sobre las dos estancias de Proust en España véase Silvan, L.: El químico francés Luis José Proust. 1754-1826, Vitoria, Gráficas Eset, 1964.

120 Proust, L.: Discurso que en la abertura del Laboratorio de Chîmia del Real Cuerpo de Artillería, establecido en Segovia, pronunció Don Luis Proust, Profesor de Chîmia del expresado Real Cuerpo, Segovia, Imp. de Espinosa, 1792.

121 Herrero FernándeZ-Quesada, op. cit. (nota 62).

122 Herrero FernándeZ-Quesada, op. cit. (nota 43).

123 Un buen número de esos trabajos y memorias de investigación, en una obra clave de la historia de la ciencia, cuyo primer tomo fue publicado por Luis Proust un año antes de que se abriera el laboratorio. Anales del Real Laboratorio de Química de Segovia, o colección de memorias sobre las artes, la artillería, la historia natural de España, y Américas, la docimástica de sus minas, Segovia, Imp. Antonio Espinosa, 1791-1795, 2 tomos. 
rentabilidad de la educación de Marte, en la formación de alumnos instruidos en los colegios de los cuerpos facultativos que fueron meditadamente seleccionados para viajar por Europa en misiones de espionaje industrial. Al margen de tan excepcionales comisiones, son casos contados.

Pero en el proceso global del reformismo ilustrado de los Borbones, eran muchos los frentes por cubrir. Como consecuencia de la innovación docente militar y, por ende, de la formación de sus oficiales, mucho se ha hablado de la militarización de la ciencia ${ }^{124}$ por las incursiones de los oficiales de los Cuerpos Facultativos en las actividades científicas, lo que llevó a Capel a afirmar que en el XVIII el científico español vestía de uniforme. ${ }^{125}$ De la misma forma, en la administración y gobiernos borbónicos encontramos -especialmente en la segunda mitad del siglo XVIII- una progresiva y cada vez mayor presencia de militares, lo que ha sido interpretado y definido por la historiografía también como una militarización de puestos importantes de la alta administración, judicatura y la política desde principios del siglo XVIII, pero especialmente notoria en su segunda mitad. ${ }^{126}$ Espacios profesionales y políticos que en el pasado no habían ocupado militares y mucho menos en una proporción tan alta, y a los que llegaron en la segunda mitad del XVIII entre otras cosas por la formación y perfil de la oficialidad, sin olvidar la relación entre las nuevas élites sociales y las redes de poder. La formación, su perfil y mérito es lo que les permite desembocar en los más importantes círculos de poder y sociales. Su aval y salvoconducto.

De esta forma, en estudios de referencia entre los que cabe destacar los del grupo PAPE que utilizan la base de datos FICHOZ, entre los servidores del Rey topamos con marinos y militares al servicio de SM no solo en las estructuras y unidades castrenses sino también en los despachos. ${ }^{127} \mathrm{Y}$ ciframos en buena medida el origen de estos nuevos destinos de los militares ilustrados en la educación de élite de aquellos oficiales que les capacitaba por ello. El estudio y seguimiento de múltiples trayectorias de militares y marinos evidencian en ese periodo una gran versatilidad profesional que ilustraremos en este trabajo con casos puntuales de artilleros.

Sin embargo, cabe señalar de entrada que los réditos de la política de innovación educativa, también los proporcionaban las propias instituciones docentes, el colectivo (los colegios y academias) y desde ellas individualidades, militares que proyectaban sus conocimientos en el programa ilustrado para el progreso de las nuevas ideas y la nueva ciencia. Ese fue el caso también del Colegio artillero y alguno de sus profesores y oficiales más señalados que volcaron sus conocimientos y amplio bagaje científico e intelectual en proyectos de cuño ilustrado como la constitución y dinamización de la Sociedad Económica de Amigos del País de la ciudad.

124 Lafuente, A., Peset, J. L.: "Militarización de las actividades científicas en la España ilustrada (1726-1754)", en PeSET, J. L. (coord.): La ciencia moderna y el conocimiento del Nuevo Mundo, Madrid, CSIC, 1985, pp. 127-147

125 CAPel, Sánchez, Moncada, op. cit. (nota 6).

126 Castellano, J. L., Dedieu, J.-P., López-Cordón, M. V. (coords.): La pluma, la mitra, la espada. Estudios de historia institucional en la Edad Moderna, Madrid, Marcial Pons, 2000.

127 Dedieu, J.-P.: "Fichoz 2011. Balance de una base de datos sobre la España moderna", en JiMÉNEZ, A., LozANO, J. J., SÁnchez-Montes, F., Birriel, M. M. (eds.): Construyendo historia. Estudios en torno a Juan Luis Castellano, Granada, Universidad de Granada, 2013, pp. 185-200; Dedieu, J.-P.: "Procesos y redes. La historia de las instituciones administrativas de la época moderna, hoy”, CaStellano, Dedieu, López-Cordón, op. cit. (nota 126), pp. 13-30. 
Como es sabido, estas sociedades contaban con el amparo de la Monarquía. La fundación de la segoviana tiene que ver en origen con el impulso de Campomanes a la apertura de estas instituciones y la recogida del guante en la década de los 70 por parte del Consejo de Castilla. ${ }^{128} \mathrm{Al}$ apoyo de la jerarquía de la iglesia y de algún notable noble local hay que sumar como seña de identidad fundacional, como elemento dinamizador de las actividades de la sociedad, la presencia en la ciudad de la academia artillera y la empatía e implicación de algunos profesores del colegio a los que se deben aportaciones muy notables. ${ }^{129}$ A la propuesta de Campomanes y la adscripción oficial de la futura Sociedad de Segovia a la de Madrid, siguieron años de parón técnico, pero el interés de algunos fabricantes de paños con proyectos en la ciudad ayudaron finalmente a su apertura. ${ }^{130} \mathrm{La}$ recuperación aunque solo fuera de una parte de la industria textil, en el pasado esplendorosa, fue uno de los objetivos de los Amigos del País lo mismo que - siguiendo las tendencias ilustradas- la renovación de las actividades agrícolas en la provincia, como demuestran las Actas de la Sociedad, que también prolijamente recogen inquietudes propiamente ilustradas por la economía, y por los problemas sociales, especialmente en el ámbito urbano.

La SEAP de Segovia se creó en 1781, en que se editaron sus Estatutos, momento en que el Colegio artillero era ya una institución de prestigio consolidado. El modelo en la fundación de las sucesivas sociedades fue la Bascongada, la primera, pero a raíz de la apertura de la de Madrid, ésta se convirtió en referente para las posteriores en todos los sentidos. Y desde la puesta en marcha de la segoviana, no se puede abordar el estudio de sus actividades sin los profesores del colegio artillero. El centro y su claustro proyectaron sus luces en las actividades de la Sociedad Económica de Amigos del País con esa energía y optimismo intelectual propios de los ilustrados.

La rentabilidad de la política de innovación educativa borbónica se manifiesta singularmente en la formación de sus oficiales que les capacitaba para la versatilidad profesional de los artilleros, en las décadas de los 80 y 90, ya hijos del Colegio y después profesores del centro. Su dilatado periodo de residencia en la ciudad, y sus inquietudes científicas e intelectuales les llevaron a implicarse en su orgánica (ocupando puestos en la Directiva) y más aún en sus actividades, resultando ser el colectivo más dinámico y editorialmente prolífico de la Sociedad.

En este trabajo, para ilustrar el caso de los artilleros y los réditos de su formación científico-técnica, en una cata nada inocente del colectivo, trataremos sobre algunos de ellos que estuvieron en el alcázar en unas décadas especialmente feraces del Colegio Artillero y de la propia SEAP. ${ }^{131}$ Los tres fueron inquietos miembros e investigadores prolíficos en materias necesarias para el progreso, pero también en principio lejanas a su área de confort profesional, de ahí su elección para ilustrar la versatilidad. Y los tres, coinciden temporalmente con la estancia en Segovia y en el Colegio de Artillero del químico francés Luis Proust como Director del Laboratorio de Chimia, quien también empatiza con las inquietudes y objetivos de la SEAP.

128 Real Cédula de S.M. y señores del Consejo por la qual se aprueban los Estatutos dela Real Sociedad Económica de Amigos del Pais. 1781. Se ha consultado la edición facsímil, Segovia, BCA, 1996, Introducción de J. M. Valles Garrido.

129 Actas y memorias de la Real Sociedad Económica de Amigos del País de la provincia de Segovia, Segovia, Imp. Antonio Espinosa, 1786.

130 García SAnz, A.: Desarrollo y crisis del Antiguo Régimen en Castilla la Vieja. Economía y sociedad en tierras de Segovia, 1500-1814, Madrid, Akal, 1977.

131 Herrero Fernández-Quesada, op. cit. (nota 119). 
Proust abundó sin duda en el contexto científico del colegio artillero, el estudio de la química y la inquietud investigadora. Este químico francés es el paradigma de la política científica borbónica que pasó por contratar extranjeros en aras del utilitarismo, consiguiendo aplicar los conocimientos científicos importados al desarrollo de la producción de la industria militar, y particularmente artillera. Sus aportaciones a la química metalúrgica imprescindible para dominar los procedimientos de fundición de cañones y bocas de fuego, fueron definitivas para que la artillería borbónica superara los retos tecnológicos que planteó el XVIII, ya mencionados en páginas anteriores. En este sentido, y para visualizar la línea investigadora, únicamente señalaremos dos de ellos. Proust recorrió diferentes establecimientos fabriles peninsulares y comprobó en la fundición de bronces de Barcelona, por métodos de análisis químico que el cobre y estaños americanos que se utilizaban, tenían un alto contenido de arsénico, lo que empeoraba la calidad del bronce de nuestros cañones. ${ }^{132}$

De la misma forma, y aplicando los mismos métodos en la fábrica de municiones de San Sebastián de la Muga demostró que la fragilidad de las municiones era consecuencia de un excesivo contenido de grafito. ${ }^{133}$ Con fundamento, por tanto, Proust en su solemne discurso de apertura del Laboratorio de Química, por fin en 1792, afirmaba que "era ya tiempo de iluminar el caos de las fundiciones con la antorcha de la química" "134, justificando al tiempo su contratación, tantas veces cuestionada y apostillando que únicamente la del técnico Maritz no resolvería los problemas de las fundiciones, por no ser un químico experto sino "un simple maquinista". En este sentido, se manifestó como hombre de su época y científico de renombre como un firme defensor -siguiendo la estela de Gazola y Eximeno- de la educación científicotécnica para los militares, como reivindica de forma magistral y didáctica en un párrafo de sus Anales donde señala las consecuencias negativas de una formación meramente práctica:

tales son las funestas resultas de aquellos métodos de enseñar en los que están reñidas la teórica y la práctica, y en que no va la ciencia acompañada de los fenómenos y delos resultados. Los alumnos de semejantes escuelas charlarán grandemente en un corrillo sobre la Química; hablarán con petimetría del calor latente, encaxarán la opinión que se hayan formado acerca del oxigeno y flogisto; pero que se les encargue un examen de un mineral... Su sabiduría es totalmente parecida a la de aquellos niños... que sabiendo hallar de golpe en un mapa Hispahan, Pekin y México, no acertarán a ir de Madrid a Caramanchel... ${ }^{135}$

$\mathrm{Y}$ en ese clima científico de altura, en el colegio de artillería y con profesores con una formación de élite adquirida en aquella academia militar desde 1764, podemos acercarnos a la rentabilidad de la educación de Marte, de los oficiales de artillería cifrada en su versatilidad profesional. En una ciudad tan pequeña y en un espacio tan reducido, entre el alcázar y el laboratorio y trabajando en torno a la excelente

\footnotetext{
Proust, L.: "Sobre el bronce", en Anales del Real Laboratorio..., op. cit. (nota 123), tomo I, pp. 335-378.

Proust, L.: "Sobre las bombas de San Sebastián de la Muga en Cataluña", en Ibidem, tomo I, pp. 5-59.

134 Proust, L.: Discurso que en la abertura del Laboratorio de Chîmia del Real Cuerpo de Artillería, establecido en Segovia pronunció Don Luis Proust, profesor de Chîmia del expresado Real Cuerpo, Segovia, Imp. A. Espinosa, 1792.

135 Recogido en el tomo II de los Anales del Real Laboratorio..., op. cit. (nota 123), pp. XVIII y XIX.
} 
biblioteca del Colegio ${ }^{136}$, se adivinan y confirman a la vez tormenta de ideas y un flujo investigador interconectado. De entre quienes coincidieron temporalmente en Segovia en esas décadas y compartiendo cátedras, cabría recordar entre otros al matemático y Jefe de Estudios Giannini, al artillero Tomás de Morla, autor de su célebre tratado, al Conde de Lacy como nuevo Director, al propio Proust, y a los capitanes García de la Huerta, Alcalá Galiano o Juan Manuel Munárriz, cuando también eran jovencísimos alumnos del centro un Cienfuegos y Jovellanos, Navarro Sangrán, o un Daoiz, Novella y La Serna, por citar tan solo algunos de ellos, pertenecientes a las promociones que por fin pudieron estudiar con los manuales, los libros de texto editados por el abate Giannini para matemáticas y Tomas de Morla para artillería.

Pero para constatar la versatilidad profesional de los artilleros y su rentable educación en la proyección de sus actividades, de entre los profesores mencionados solo nos centraremos en las aportaciones científicas de tres capitanes, García de la Huerta ${ }^{137}$, Munárriz ${ }^{138}$ y Alcalá Galiano ${ }^{139}$ pues resultan ser perfectos para ilustrar la rentable educación de Marte en el XVIII, por su versatilidad profesional, sus inquietudes intelectuales y -especialmente- un aspecto que comparten: su trabajo bien como traductores científicos o como autores de trabajos y opúsculos inéditos y muy necesarios en la España Ilustrada. Los tres compartían claustro y por tanto destino en el Colegio segoviano en la misma época y vínculos estrechos con la SEAP en la que asumieron cargos en la directiva y, sobre todo, participaron como activos miembros y autores de trabajos notables y más que reseñables que dan a las Actas de la Sociedad y a las publicaciones impulsadas por la institución un elevado tono científico.

Este grupo, en esos años, dio a imprenta traducciones y ensayos imposibles de obviar a la hora de poner de manifiesto los réditos de la educación ilustrada de los oficiales dieciochescos, en este ámbito de la investigación y divulgación científica y de la aplicación práctica de estos conocimientos. Como autor, reviste especial interés la obra del capitán Luis García de la Huerta ${ }^{140}$ quien conciliando sus obligaciones docentes en el Colegio, dedicó horas y desvelos a la investigación sobre un tema, prioritario para la SEAPS y de absoluta actualidad en Europa y en España, con fuertes fundamentos químicos, por cierto. En 1779 publicó su Discurso físico-anatómico sobre las plantas un estudio propio sobre un tema nada afín a la milicia pero próximo a la ciencia y de interés general y social, objeto de desvelos por parte del reformismo ilustrado que buscaba lograr un modelo de nueva agricultura, y el progreso en su conocimiento y cultivo. Como traductores los tres aportan obras muy necesarias para la divulgación científica, pero destaca sobremanera Juan Manuel Munárriz quien tiene en su haber, ser el primer traductor del Tratado elemental de química de Lavoisier,

136 Véase sobre la composición y fondos de aquella biblioteca García Hourcade, J. L., VAlLES Garrido, J. M.: Catálogo de la Biblioteca del Real Colegio de Artillería. I. Fondos científicos, Segovia, BCA, 1989; Herrero FernándeZ-Quesada, op. cit. (nota 54); y Herrero FernándeZ-Quesada, M. a D.: "Notas sobre los fondos impresos y documentales de la Biblioteca de la Academia de Artillería y el Archivo Histórico Militar", en Estudios Segovianos, 94 (1996), pp. 349-388.

137 AGMS, sección $1^{\mathrm{a}}$, división 1a , leg. G-1477. Expediente Personal de Luis García de la Huerta.

138 AGMS, sección $1^{\mathrm{a}}$, división 1 ${ }^{\mathrm{a}}$, leg. M-4752. Expediente Personal de Juan Manuel Munárriz.

139 AGMS, sección 1 ${ }^{\mathrm{a}}$, división 1ª , leg. A-1045. Expediente Personal de Vicente Alcalá Galiano.

140 García de la Huerta, L.: Discurso fisico-anatómico sobre las plantas, dirigido a los agricultores y presentado a la Real Sociedad Económica de Amigos del Pais de Segovia, Segovia, Imp. Antonio Espinosa, 1779. Según reza en la portada de su obra ya por entonces era Socio Honorario y correspondiente de las Sociedades Económicas de León, Mallorca, Vera, Velez-Málaga etc. 
impreso tan solo nueve años después de su edición en Francia ${ }^{141}$, hito importante de la historia de la ciencia ilustrada. Y no solo eso, el químico Luis Proust permitió que firmase y publicase en su obra de investigación Anales del Real Laboratorio, la traducción del francés de una memoria del Doctor Fizes "sobre la purificación del cristal de tártaro". ${ }^{142}$

Sin embargo, centraremos nuestra atención especialmente en el prolífico capitán Vicente Alcalá Galiano, por sus inquietudes científicas e intelectuales mostradas en trabajos como las traducciones de tres textos temáticamente bien dispares pero que focalizan las prioridades del ideario ilustrado y, por tanto, las líneas de trabajo de las Sociedades Económicas. El año 1786 fue notablemente fructífero, y Galiano vio editadas tres de sus traducciones más señeras, por cierto dos de ellas del francés y una del italiano, dato revelador del perfil y formación del oficial. Se trata de tres textos que circulaban por Europa de temática ilustrada. La Memoria sobre los diferentes modos de administrar la electricidad y observaciones sobre los efectos que estos diversos modos han producido ${ }^{143}$ del francés MAUDUIT; La meteorología aplicada a la agricultura, del Abate Josef TOALDO ${ }^{144}$ y la traducción de una interesante memoria absolutamente alineada con el campomanismo Ideas sobre la naturaleza, forma y extensión de los socorros que conviene dar a los enfermos pobres en una ciudad populosa. ${ }^{145}$

Como autor cabe señalar un trabajo presentado a la SEAPS coincidente con las inquietudes de García de la Huerta y del grueso de los socios de la SEAPS, un ensayo propio, sobre Preservativo seguro de la enfermedad del trigo comunmente llamada niebla o tizón. ${ }^{146}$ Esta obra abunda en el interés de los ilustrados y de las propias Sociedades por el tema de la agricultura, objeto de investigación y de numerosos estudios en la España de finales del XVIII, incluso con prensa especializada en la época. ${ }^{147}$ En la obra de Alcalá Galiano siempre estuvo presente, enfatizando su importancia clave para el futuro de la economía de un estado con alegorías como la que sigue "El Estado es un Arbol, sus Raices, la Agricultura, su Tronco, la Población; sus Ramas, la Industria; y el Comercio propiamente dicho y las Artes, sus Hojas". ${ }^{148}$

Pero si del grupo de profesores llama la atención la figura de Alcalá Galiano, es porque personifica singularmente la versatilidad de los oficiales y la rentabilidad

141 Lavoisier, A.: Tratado elemental de química. Traductor J. M. Munarriz, Madrid, Imp. Real, 1798.

142 Editada en el tomo II, pp.89-103.

143 Memoria sobre los diferentes modos de administrar la electricidad y observaciones sobre los efectos que estos diversos modos han producido. MAUDUIT. Traducida del francés por el capitán Vicente Alcalá Galiano de orden de la RSEAP de la provincia de Segovia, Segovia, Imp. A. Espinosa, 1786. Sin embargo no quedó en mero traductor, alentado por el Jefe de Estudios del Colegio artillero, Pedro Giannini, experimentó sobre un paisano de la provincia de Segovia con dificultades de movilidad, una terapia por medio de la administración de electricidad. Véase Herrero Fernández-Quesada, op. cit. (nota 119).

144 Todldo, Abate J.: La meteorología aplicada a la agricultura. Traducida del italiano por el Capitán Vicente Alcalá Galiano Segovia, Imp. de Espinosa, 1786. Esta traducción es pionera en España, en unos años en que se incrementaba el interés por la meteorología siguiendo las tendencias científicas dela Europa ilustrada, que también llegaron a la España de Carlos III y Carlos IV, prueba de ello es la edición ocho años después de GARriga, J.: Curso Elemental de meteorologia, Madrid, Imprenta Real, 1794.

145 Traducida del francés por el capitán ALCALA GALIANO. Segovia, Imp. A. Espinosa, 1787

146 Opúsculo editado en Segovia, Imprenta de Antonio Espinosa, 1788.

147 Larriba, E., Dufour, G.: El Seminario de Agricultura y Artes Dirigido a los Párrocos (1797-1808), Valladolid, Ámbito, 1997.

148 Alcalá Galiano, V.: "Sobre la industria en general y sobre los medios de promoverla en esta provincia", en Actas y Memorias de la Real Sociedad Económica de los Amigos del País de la provincia de Segovia, Segovia, Imp. A. Espinosa, 1785, pp. 55-73. La memoria está fechada en 1781. 
de las inversiones en innovación educativa en el XVIII. Con Vicente Alcalá comprobamos cómo este oficial de artillería de divulgador científico durante esos años transita hacia una nueva ciencia emergente. Y tiene que ver con su dedicación y alta especialización en la que entonces se empezó a denominar "economía política", singularmente en su vis impositiva, en el ámbito de la tributación y los impuestos, lo que finalmente le llevó a ocupar puestos elevados en los despachos al servicio del Rey, y lejos de la artillería. ${ }^{149}$ De hecho, en 1787 fue nombrado alto funcionario a las órdenes del Superintendente General de Hacienda, reventando las costuras del uniforme y pasando a desempeñar trabajo de gabinete en los despachos durante el ministerio del Conde de Lerena y, después con el ministro Gardoquí fue nombrado Director General de Rentas. Los avatares políticos, económicos y hacendísticos del final de siglo afectaron al funcionario Alcalá Galiano, por su antigodoyismo manifiesto $^{150}$, llegando finalmente en 1808 a ser nombrado Tesorero General. ${ }^{151}$

Su cualificación y conocimientos de la economía y las tendencias imperantes en la Europa de la Ilustración, así como de los impuestos y las necesarias reformas tributarias llevan a este Alcalá Galiano, descendiente de militares pero lector de Adam Smith y otros autores que estaban marcando la reformulación de la economía en Europa, a dedicarse profesionalmente a la economía política, siendo el caso de versatilidad más potente. De Cadete, luego oficial y profesor de matemáticas en el Colegio Artillero y miembro activo de la SEAP con traducciones y publicaciones de disciplinas científicas varias, a la Corte, al desempeño de especializados trabajos en el ámbito de la fiscalidad del Ministerio de Hacienda y también conviene recordar que en momentos más que delicados para las arcas de la Monarquía, necesitada de soluciones.

La saga de los Alcalá Galiano tenía sus contactos en Madrid y relaciones en diferentes y altas instancias. En este caso, el artillero contaba también con un buen capital relaciona ${ }^{152}$ para dar el salto de Segovia a Madrid, de la artillería a la economía política. Pero parece que el capitán fue llamado a la Corte por su notable especialización en la economía política y los impuestos a la que dedicó lecturas y trabajos en su etapa académica. De hecho, fueron sus trabajos sobre tan novedosa ciencia impulsados por la SEAP y publicados en sus Actas como Memorias y opúsculos, las que le llevaron a ocupar un importante despacho en el Ministerio de Hacienda. La Monarquía no tenía fácil encontrar perfiles cualificados en estos asuntos y, en este caso, por sus obras le conocieron y le reclamaron, en un momento del siglo en que a los despachos se llegaba por mérito, sin duda, pero también por las relaciones y las efectivas redes de las élites de poder. ${ }^{153}$ De la misma forma, debemos recordar aquí que

149 AGMS, Sección 1 ${ }^{\mathrm{a}}$, leg. A-1045. Expediente Personal de V. Alcalá Galiano

150 Véase el testimonio de su sobrino Alcalá Galiano, A.: Memorias de Don Antonio Alcalá Galiano, Madrid, s.i., 1886.

151 En el Estudio Preliminar de J. M. Valles Garrido a la edición facsímil de Alcalá Galiano, V.: Sobre la economía política y los impuestos, Segovia, BCA, 1992.

152 Imízcoz BeunZa, op. cit. (nota 28).

153 Véanse Imízcoz Beunza, J. M.: Élites, poder y red social. Las élites del País Vasco y Navarra en la Edad Moderna, Bilbao, Servicio editorial: Universidad País Vasco, 1996; Imízcoz BeunzA, J. M.: “Actores, redes, procesos: reflexiones para una historia más global”, Revista da Faculdade de Letras, 5 (2004), pp. 115-140; Imízcoz BeunzA, J. M.: "Élites administrativas, redes cortesanas y captación de recursos en la construcción social del estado moderno", Trocadero, 19 (2007), pp. 11-30; Imízcoz BeunZA, J. M.: "Las élites vasco-navarras y la monarquía hispánica: construcciones sociales, políticas y culturales en la Edad Moderna", Cuadernos de Historia Moderna, 33 (2008), pp. 89-119; Imízcoz BeunzA, J. M.: "La 'hora del XVIII'. Cambios sociales y contrastes culturales en la modernidad política española”, Príncipe de Viana, 254 (2011), pp. 37-64; así como 
se hablaba abiertamente de militarización de la administración como consecuencia del importante número de oficiales que ocupaban gabinetes ${ }^{154}$, como señaló Andújar especialmente para la segunda mitad del siglo XVIII. Por entonces, la historiografía ha puesto de manifiesto la naturaleza de los cambios en las Secretarías del Despacho $\mathrm{y}$, en ese contexto, el nutrido desembarco de militares. ${ }^{155}$

Destacaremos dos de estos trabajos que suscitaron debate apasionado y trascendieron las lindes del Colegio de Artillería y de la propia RSEAP: Perjuicios del antiguo sistema de Rentas Provinciales... Memoria presentada a la Real Sociedad Económica de Segovia ${ }^{156}$; y Sobre la necesidad y la justicia de los tributos y fondos de donde deben sacarse y medios de recaudarlos. Memoria presentada a la Sociedad Económica de Segovia. ${ }^{157}$

En Europa a mediados del XVIII se empieza a especular en torno a lo que ya iba tomando cuerpo como economía política. Y siendo Alcalá Galiano matemático y resultando ser las matemáticas imprescindibles para el desarrollo y comprensión de la nueva economía política, con la curiosidad intelectual que le acompañó toda su vida, se sumergió en todo lo que tenía que ver con esta nueva materia tan alejada disciplinadamente de las científicas. Con una fuerte influencia en su obra de Rousseau en los primeros escritos sobre economía política y después de A. Smith ${ }^{158}$, Alcalá Galiano en sus ensayos denunciaba en España "poco aprecio y casi total abandono que la economía política padecía entre nosotros". ${ }^{159}$

En sus trabajos editados sobre la nueva economía política, y distinguiendo conceptualmente la economía doméstica de la del Estado, la entendía planteada solo en aras del interés común de la patria de ahí que para Alcalá Galiano "la Economía Política debe ser un perpetuo centinela que incesantemente vigile en el aumento de este común interés, y que quite todos los estorbos y dificultades que se oponen a su importante adelantamiento". ${ }^{160} \mathrm{Y}$ a ello dedicó numerosas publicaciones sobre las leyes que debían regular esta disciplina para el buen gobierno del Estado, sobre las rentas y su diferente naturaleza y finalmente sobre los impuestos y su gestión. Entre estos últimos cabe destacar su memoria sobre "la necesidad y justicia de los tributos,

Imízcoz Beunza, Oliveri Korta, op. cit. (nota 28).

154 AndúJar, F.: "Poder militar y poder civil en la España del siglo XVIII: Reflexiones para un debate", Mèlanges de la Casa de Velázquez, 28-2 (1992), pp. 55-70; véanse también CaSTellano, Dedieu, LóPez-Cordón, op. cit. (nota 126); y FrANCO, G.: “¿Espada o pluma?, ¿destino militar o puesto administrativo? La incorporación de los militares a las instituciones civiles en la España del siglo XVIII”, Cuadernos de Historia Moderna, 18 (1997), pp. 69-86.

155 Entre otros cabe citar Nava, T., López-Cordón, M. V., Franco, G.: "Perfiles socio-profesionales de la burocracia española en el siglo XVIII: las Secretarías de Estado y del Despacho", ENCISO RECIO, L. M. (coord.): La Burguesía Española en la Edad Moderna: actas del Congreso Internacional, Valladolid, Universidad de Valladolid, 1996, vol. II, pp. 1009-1034; NaVA, T.: "Problemas y perspectivas de una historia social de la administración: los Secretarios del Despacho en la España del siglo XVIII”, Mèlanges de la Casa de Velázquez, 30 (1994), pp. 151-166; y CASTEllano, J. L.: "Redes sociales y administración en el Antiguo Régimen", Estudis. Revista de Historia Moderna, 31 (2005), pp. 85-102.

156 Memoria publicada en Actas y Memorias de la Real Sociedad Económica de los Amigos del País de la provincia de Segovia, Segovia, Imp. A. Espinosa, 1787.

157 Publicado en Actas y Memorias de la Real Sociedad Económica de los Amigos del País de la provincia de Segovia, Segovia, Imp. A. Espinosa, 1788, tomo IV.

158 Para una aproximación al tema véase el Estudio Preliminar de J. M. Valles Garrido, a la edición facsímil de Alcalá Galiano, op. cit. (nota 150).

159 Alcalá Galiano, V.: "Sobre la Economía política”, en Actas y Memorias de la Real Sociedad Económica de los Amigos del País de la provincia de Segovia, Segovia, Imp. A. Espinosa, 1785, pp. 55-73. La memoria está fechada en 1783 . 
fondos de donde deben sacarse, y medios para recaudarlos"161, en la que ya se detecta la potente y principal influencia que tuvo A. Smith en las teorías fiscales de Alcalá Galiano. Destacamos un párrafo sobre la tributación:

La recaudación de los tributos debe hacerse causando los memores perjuicios a los contribuyentes, quienes pueden recibir mayores daños de las formalidades y trabas que se establezcan para la seguridad del impuesto que del impuesto mismo. La ciencia fiscal ha procedido muchas veces contra esta provechosa máxima, y ha ocasionado una infinidad de desórdenes que parten del mismo errado principio; a saber, de figurarse que con las leyes penales y opresiones se lograría el aumento del erario. No es decir con esto que como pretenden los Economistas no haya confiscaciones y multas pecuniarias proporcionadas contra los que procuran sustraerse de pagar los derechos establecidos, sino que se deben calcular antes con la mayor madurez y pulso los daños que pueden seguirse de dichas leyes y opresiones, para compararlos con las ventajas que se esperan o deben esperarse de ellas: lo que exige mucha meditación y mucho estudio. ${ }^{162}$

Alcalá Galiano era un hombre de su tiempo, militar, pero funcionario al servicio de la Monarquía, a quien su formación científico-técnica, especialmente su excelente base matemática, sus inquietudes intelectuales y sus amplias lecturas y trabajos le llevaron convertirse en experto en temas de fiscalidad y hacendísticos. Su Hoja de Servicios se cierra pronto sin haber entrado verdaderamente en campaña "en ninguna hasta el día de la fecha"163, por haber estado destinado en el tan acertadamente llamado Seminario de Segovia, donde tuvo la excelente biblioteca del centro como espacio de investigación cotidiano y predilecto. Su trayectoria es explicita en lo que concierne a su versatilidad profesional, y su polivalencia disciplinar hunde sus raíces en sus años de formación en el colegio artillero, paradigma de la rentabilidad del nuevo modelo diseñado para la educación de Marte. El mismo, se reconocía un servidor de la Monarquía, allá donde fuera de utilidad independientemente del destino que ocupara, de tal forma que transitando con naturalidad de la milicia más científica a la economía política, se confesaba servidor "de la Causa Pública, en cuyo servicio siempre que me empleo, me considero el más feliz de los Hombres". ${ }^{164}$

161 Publicada en Actas y Memorias de la Real Sociedad Económica de los Amigos del País de la provincia de Segovia, Segovia, Imp. A. Espinosa, 1793, tomo IV, pp. 269-358. La memoria está fechada en 1788.

162 Ibidem, p. 323.

163 AGMS, sección 1 ${ }^{a}$, división 1 ${ }^{\mathrm{a}}$, leg. A-1045.Expediente Personal. Su última Hoja de Servicios se cierra en 1786, cuando causa baja en el ejército y parte hacia la Corte a prestar sus servicios en los despachos.

164 Alcalá Galiano, V.: "Sobre la Economía política”, en Actas y Memorias de la Real Sociedad Económica de los Amigos del País de la provincia de Segovia, Segovia, Imp. A. Espinosa, 1785, pp. 55-73. La memoria está fechada en 1783. 